\title{
"AND IF YOUR FRIENDS JUMPED OFF A BRIDGE, WOULD YOU DO IT TOO?: How DeVELopmental NEUROSCIENCE CAN INFORM LEGAL REGIMES GOVERNING ADOLESCENTS
}

\author{
Michael N. Tennison* \& Amanda C. Pustilnik**
}

I. INTRODUCTION 534

II. LEGAL REGIMES CONSTRAINING ADOLESCENT AUTONOMY:

A TYPOLOGY 543

A. Recent Supreme Court Holdings Recognize Juvenile

Developmental Difference. 543

B. A Typology of Legal Approaches to Adolescent Autonomy and Responsibility.... 546

1. Total Denials of Autonomy ................................... 546

2. Delegated Autonomy ............................................ 548

3. Graduated Autonomy.......................................... 550

4. Total Autonomy................................................. 552

5. Censure-Based Responsibility .............................. 553

C. The Result-Multiple Regimes Lead to Inconsistent

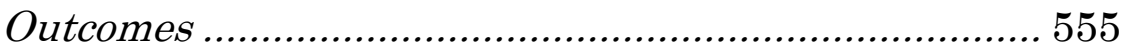

III. How - AND WHY - AdOLESCENTS ARE DIFFERENT ....... 556

A. The Brain's Adolescence ....................................... 556

B. Developmental Disparity Between PFC and Limbic

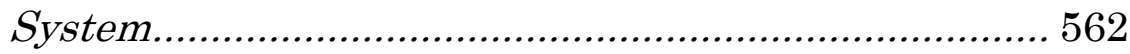

C. Emotional Control and Reactivity.......................... 563

D. Reward and Impulsivity ....................................... 565

IV. Three CASEs of Juvenile LaW ANALYZED VIA

NEURODEVELOPMENTAL CRITERIA ..................................... 566

A. The Case of Tattooing......................................... 567

$B$. The Case of Alcohol, Tobacco, and Other Addictive

Substances..... 571

* J.D., M.A. [Bioethics]. Research Fellow, University of Maryland Thurgood Marshall Law Library.

** Professor of Law, University of Maryland; faculty member, Center for Law, Brain, and Behavior, Massachusetts General Hospital. Michael Tennison and I are grateful to Jennifer Drobac and the Indiana University Robert H. McKinney School of Law, Hall Center for Law \& Health for convening this Symposium. 
C. Intentional Violence............................................ 578

1. Scenario A: Vulnerable to Violence ....................... 580

2. Scenario B: Deliberate Violence ............................ 584

V. RECOMMENDATIONS \& CONCLUSION............................... 585

\section{INTRODUCTION}

On September 17, 2014, a teen boy riding in the front seat of an SUV on the highway at night had a brilliant idea: If he set the driver's armpit hair on fire, it might impress the girls in the back. It did not turn out quite the way he planned. "Teen Setting Underarm Hair On Fire Causes Rollover Crash," reported news outlets the next day. ${ }^{1}$ The SUV ran into a ditch, flipped over, and threw three of the five occupants-all teenagers, none of whom were wearing seat belts-out onto the highway. Miraculously, no one was killed. ${ }^{2}$

This story is humorous and serious all at once. Humorous, because it embodies a head-shaking truth long acknowledged in our and other cultures about the crazy things kids do. Serious, because the thoughtless yet typical action of one boy could have seriously hurt or killed these four children and possibly other people on the highway that night. And it has a serious message: Teens are different from adults, on average, particularly in ways that relate to the overvaluation of present rewards and sensations, the undervaluation of negative risk, the tremendous salience of their desire for peer approval, and their tendency to act in

\footnotetext{
1 Deputies: Teen Setting Armpit Hair on Fire Causes Rollover Crash, KHOU.com (Sept. 18, 2014, 5:36 AM), http://www.khou.com/story/news/weird/2014/09/18/deputies-teensetting-armpit-hair-on-fire-causes-rollover-crash/15815971/. See also Jason Molinet, Lighting Driver's Armpit Hair on Fire Caused Idaho Rollover Crash: Cops, NEW YoRK DAILY News (Sept. 17, 2014, 11:10 PM), http://www.nydailynews.com/news/national/armpit-hair-firecaused-idaho-rollover-crash-cops-article-1.1943702; Ashton Edwards, Burned armpit hair prank ends in teens rolling SUV, FOX13 SALT LAKE CITY (Sept. 18, 2014, 12:40 PM), http://fox13now.com/2014/09/18/ burned-armpit-hair-prank-ends-in-teens-rolling-suv/.

2 See id.
} 
even more risky and thoughtless ways when they are together in groups. ${ }^{3}$

We do not need neuroscience to tell us adolescents are different. Cultures have recognized adolescent differences for a long time in a variety of ways. ${ }^{4}$ Our laws already recognize that adolescents are different from adults, limiting their autonomy or modifying their responsibility in myriad ways. ${ }^{5}$ Yet, we may benefit from new findings in the field of juvenile developmental neuroscience to help us understand exactly how and why teens are different from adults, and how our laws might do a better job of determining where to grant or limit autonomy and where to impose or mitigate responsibility.

The ways our laws account for juvenile differences are highly inconsistent. In some areas, the law allows juveniles dramatically less autonomy than adults, but in other areas the law imposes adult-equivalent punishment and responsibility. ${ }^{6}$ Contradictions between bodies of law are not in themselves necessarily problematic: Different branches of law have different aims and normative underpinnings, and may balance the interests of different sets of stakeholders; accordingly, provided a body of law is internally consistent, varying or conflicting constructs across bodies of law may result from their different purposes. ${ }^{7}$ However, these contradictions do become

3 See infra Part II.

4 See, e.g., Richard M. Dunham \& Jeannie S. Kidwell, Rites of Passage at Adolescence: A Ritual Process Paradigm, 1 J. ADOLESCENT RESEARCH 139 (1986) (exploring how rites of passage facilitate the transition from adolescence to adulthood).

5 See infra Part I (explaining how different legal regimes carve out different forms of treatment for minors).

6 See infra Part I.B. (contrasting how the law totally denies adolescent autonomy in some areas, such as voting, but attributes full adult responsibility to other adolescent actions, such as the commission of certain crimes).

7 Consider again voting in contrast with adolescent crime. The different legal treatment of minors and adults with respect to voting serves the societal interest in informed decision-making, and the law plausibly draws a bright line at the age of majority. In the case of adolescents tried as adults in criminal cases, the law serves an entirely different purpose: to punish offenders and deter potential offenders. 
problematic when they arise, or are claimed to arise, from the same source. If each domain of law that governs juveniles differently from adults purports to do so based upon juveniles' different capacities, and then those domains embody different or contradictory notions of adolescent capacities, then they are in conflict. 8

The law acknowledges the liminal developmental status of adolescents in a variety of ways. The criminal law incorporates a notion of developing responsibility, providing for no criminal responsibility for infants and toddlers children, an intermediate level of sanction for young children, a higher but non-adult level of penalty for young adolescents and teens who commit less serious crimes and, often, full adult responsibility for teens who commit serious crimes. ${ }^{9}$ This criminal law approach implies a linear model of development: Youth start out with little or no capacity for responsibility and gain it gradually but globally as they mature; if they engage in serious or adult-like crime, however, then they must be capable of experiencing adultlike consequences. ${ }^{10}$ In contrast to the criminal law's linear continuum model, other areas of law afford autonomy or ascribe responsibility using an on-off toggle of age, based on a bright-line age cutoff. Minors under eighteen may enter into but may electively void contracts, a regime that allows the minor to exercise autonomy but protects him or her from some of the commensurate responsibility. ${ }^{11}$ Other well-known on-off "toggle" laws prohibit individuals under eighteen from voting and buying tobacco and those under

8 Since, for example, voting laws and criminal laws both account for the fact that adolescents suffer from a kind of impaired decision-making by virtue of being adolescents, and yet they come to contradictory conclusions, these legal regimes are in conflict.

9 See 2 Subst. CRIM. L. § 9.6 ( 2 d ed.).

10 See infra Part I.A.

11 See Restatement (SECOND) of Contracts § 14 (1981) ("Unless a statute provides otherwise, a natural person has the capacity to incur only voidable contractual duties until the beginning of the day before the person's eighteenth birthday."). 
twenty-one from consuming alcohol. ${ }^{12}$ The patchwork of laws across the country shows lawmakers' disagreement, ambivalence, or confusion about juvenile autonomy and responsibility, as well as about the underlying actions being regulated. Thus, not only do the current legal models of adolescent decision-making capacity appear inconsistent across legal domains, they also produce apparently inconsistent results within a given legal sphere.

This essay first introduces a descriptive framework that creates a typology of existing state laws relating to the regulation of adolescent autonomy and responsibility. ${ }^{13} \mathrm{We}$ categorize existing legal approaches to juveniles as consisting of total denials of autonomy, delegated autonomy, graduated autonomy or responsibility, revocable autonomy, and total autonomy. ${ }^{14}$ This typology is necessarily imperfect because the underlying material it describes is internally muddled, resisting neat categorization. It is also imperfect because of the interplay of the concepts-and the facts - of autonomy and responsibility. ${ }^{15}$ This categorization attempt, though, reflects some genuine differences between various bodies of law and may help to show with some greater clarity the variety of approaches that the law employs when regulating adolescent autonomy and responsibility.

In criminal law, there is theoretically a continuum of responsibility based on age and the harm caused-so the younger the juvenile, the less responsible. ${ }^{16}$ In reality, however, the law tends to toggle responsibility on or off based on the magnitude of harm, or, in other words, "adult time for an adult crime." 17 This emerged as part of the tough on crime movement during the 1980 s that

12 See, e.g., Your Rights and Responsibilities as a Minor, Tenn. COMM'N ON CHILDREN AND YouTH, https://www.tn.gov/assets/entities/ tccy/attachments/om-rr-14.pdf (last visited Aug. 12, 2015).

13 See infra Part I.

14 See infra Part I.B.

15 See infra Part I.B.

16 See supra note 9.

17 See David L Hudson Jr., Adult Time for Adult Crimes, ABA JOURNAL (Nov. 2, 2009) http://www.abajournal.com/magazine/ article/adult_time_for_adult_crimes/. 
significantly reformed juvenile law. ${ }^{18}$ So rather than doing a close examination of whether a particular juvenile is mature to a particular degree, criminal law looks mostly at the external factor-the crime committed.

If a juvenile causes serious harm, the reasoning holds that what we have is a hardened, adult-like criminal in a child's body, not a significantly flawed, juvenile thought process, such as not understanding risk or making good risk/reward calculations. ${ }^{19}$ Not understanding risk leads to the kind of bad judgment that causes you to light your friend's armpit hair on fire while he is driving a 2000-pound SUV on the highway at night.

A closer look at the empirical difference between adolescents and adults could produce a more coherent paradigm of juvenile decision-making capacity and responsibility. The rapidly advancing field of developmental neuroscience has produced a wealth of knowledge that, when evaluated in relation to the interests of relevant stakeholders, could help legal scholars and lawmakers rethink areas of law pertaining to juveniles. ${ }^{20}$ Responsibility entails a bundle of cognitive and social capacities that cannot be reduced to a simple continuum that runs from childhood nonresponsibility through to adult responsibility. ${ }^{21}$ Juveniles do not simply become more neurologically and socially adult-like across the board as they get older. Instead, different parts of the brain and various decision-making capacities develop at different rates, and frequently may not develop in a linear fashion. ${ }^{22}$

18 See, e.g., Juvenile Justice History, CTR. ON JUVENILE AND CRIMINAL JUSTICE, http://www.cjcj.org/education1/juvenile-justicehistory.html (last visited Aug. 11, 2015).

19 See infra Part II.

20 See, e.g., Jennifer H. Pfeifer \& Sarah-Jayne Blakemore, Adolescent Social Cognitive and Affective Neuroscience: Past, Present, and Future, 7 Social Cognitive And AfFective Neuroscience 1 (2012) (evidencing the range of neuroscientific interest in the adolescent brain).

21 See, e.g., Leah H. Somerville \& B.J. Casey, Developmental Neurobiology of Cognitive Control and Motivational Systems, 20 CURRENT OPINION IN NEUROBIOLOGY 236, 236 (2010).

22 See infra Part II. 
Adolescents may be more prone to certain risks and influences than adults, yet display other cognitive abilities that are on average equal to those of adults. ${ }^{23}$

Adolescents' particular deficits include susceptibility to peer influence, overvaluation of emotional information, a predilection for novelty, and poor impulse control. ${ }^{24}$ On the other hand, they appear to function equivalently to adults on many cognitive tasks. ${ }^{25}$ Adolescents may even outperform adults in some areas related to speed of cognitive or computational processing. ${ }^{26}$ Adolescents vary from each other, just as all individuals do. Certain adolescents, like certain adults, may be unusually responsible or unusually impulsive. ${ }^{27}$ Different adolescents vary, too, in their degree of education, supervision, mentorship, and life experience. All of these factors contribute to whether any individual adolescent is a better or worse decision-maker. However, across the age group, the differences identified above are persistent, although in degree they may vary. These differences in capacities and

23 Linda S. Gottfredson, The General Intelligence Factor, ScI.

Amer. Presents: Human InTELligence 24, 29 (1998), https://www.udel.edu/educ/gottfredson/reprints/1998generalintelligencef actor.pdf ("Individual IQ levels tend to remain unchanged from adolescence onward, and despite strenuous efforts over the past half a century, attempts to raise $g$ permanently through adoption or educational means have failed.").

24 See Infra Part II.

25 See Gottfredson, supra note 23.

26 See, e.g., Joseph J. Thompson et al., Over the Hill at 24: Persistent Age-Related Cognitive-Motor Decline in Reaction Times in an Ecologically Valid Video Game Task Begins in Early Adulthood, 9 PLOS ONE e94215 (Apr. 9, 2014), available at http://www.plosone.org/ article/fetchObject.action?uri=info:doi/10.1371/journal.pone.0094215\&re presentation $=$ PDF.

27 Rhoshel K. Lenroot \& Jay N. Giedd, Brain Development in Children and Adolescents: Insights from Anatomical Magnetic Resonance Imaging, 30 NeuRosci. \& BiobeHAVIORAL REV. 718, 718-29 (2006) (noting significant individual variability in development, including significant overlap in developmental trajectories between typically and psychiatrically abnormal adolescents; this work suggests that conclusions about abnormalcy versus typicality should not be made based on brain scans alone and conclusions should be reserved until relatively developmentally late in the life course). 
abilities emerge from adolescents' particular stage of neurological and psycho-social development, combined with adolescents' necessarily more limited life experience. ${ }^{28}$

This mosaic of adolescent differences and similarities to adults suggests, first, that a uniform legal autonomy and responsibility discount-say, a regime that would relieve adolescents of all forms of responsibility and of personal agency, equally-would be inappropriate. It similarly suggests that the ways in which bodies of law currently modify responsibility and punishment regimes for juveniles may be inaccurately or incompletely drawn: In most areas, the law focuses on factors peculiar to the legal context, such as the importance of the right in question, like the right to bodily integrity, or the severity of the harm that the adolescent caused, as in a crime of violence. ${ }^{29}$ An emphasis on the importance of the legal right or the extent of the social harm is important, but such concerns are external to and independent of whether an adolescent has appropriate decisional capacity in that context. ${ }^{30}$ Legal regimes need to consider both together: It is the combination of the features of the relevant legal context and of the particular developmental capacities and vulnerabilities that ought to shape legal regimes relating adolescents.

At its worst, current law relative to adolescents is an inconsistent and internally contradictory patchwork. At its best, the law operates with an implicit idea of linear development, a continuum that suggests that juveniles mature at an even rate, gradually gaining autonomy and responsibility as they age. ${ }^{31}$ Even this continuum, however, is problematic in light of how juveniles mature and the very

\section{See id.}

29 See, e.g., Laurence Steinberg, Should the Science of Adolescent Brain Development Inform Public Policy?, 28 Issues 3 (2012), available at http://issues.org/28-3/steinberg/ (discussing a fact-specific analysis of juvenile responsibility in a case of felony murder).

30 See id. (contextualizing the severe effect of felony murder-the death of an innocent person-with neuroscientific evidence of adolescent impulsivity, vulnerability to peer pressure, and short sightedness).

31 See infra Part I.B.3. (describing how some legal regimes, such as those governing drivers licensing, may allow for several stages of increasing autonomy as the adolescent matures). 
different practical and social considerations that operate across different legal contexts. ${ }^{32}$ In the place of the patchwork and the continuum, we propose a matrix. A matrix permits lawmakers to appropriately consider the interrelationships between juvenile developmental neurobiology, the interests of other stakeholders, the institutional capacities implicated in particular legal regimes, and the relevant social norms. We suggest that lawmakers think of the relationship between juvenile neurodevelopmental factors, legal and social norms, stakeholder interests, and institutional considerations, as relating in the following way: Imagine a set of juvenile capacities and vulnerabilities on one axis of a matrix. The other axes of the matrix consist of the interests of other stakeholders, the capacities of institutions, the presence of important or controlling social norms, and the signaling function of the law. Like the neurodevelopmental information itself, the matrix does not determine the particular outcome. Rather, it allows for clarity about the choices and trade-offs within any particular legal regime.

Although the matrix concept may at first appear complex, it would provide a very simple tool for lawmakers who want to generate socially and normatively appropriate yet neurobiologically informed legal regimes. Even binary regimes can be compatible with this matrix concept. Take for example the context of alcohol consumption: Alcohol is immediately gratifying, is frequently highly socially influenced, enhances impulsivity, and creates great and harmful externalities. ${ }^{33}$ The right output from the matrix would be "no alcohol consumption until 21" (or later), an age at which the peculiar deficits of adolescence are less salient and, socially, the intense peer environments of high school and college are behind the typical young person.

32 See Steinberg, supra note 29 (explaining that the adolescent brain does not simply become more adult-like as the teenager ages: intellectual maturity arrives far sooner than emotional maturity).

33 See, e.g., David J. Nutt et al., Drug Harms in the UK: A Multicriteria Decision Analysis, 376 LANCET 1558, 1561 (2010) (ranking the harms to self and to others of common drugs of abuse). 
This idea of an adolescent responsibility matrix is not meant to suggest the individualization of justice based on each adolescent's particular maturity. Such individualization-even if it were possible, which it is notwould not only be prohibitively expensive and inefficient, but would create excessive uncertainty in the law. ${ }^{34}$ An adolescent has to know, or at least be able to know, the operation of the law in advance so that he or she can plan and act appropriately. ${ }^{35}$ Any fully individualized regime would require an adolescent_-or any party dealing with an adolescent-to gamble in advance on what some legal maturity determination might show down the line, which would be impractical at best and dangerous at worst.

This can and should inform legal notions of responsibility, and accordingly, responsibility should be conceived of in a matrix rather than a one-dimensional continuum. By matching developmentally disparate brain regions and their associated decision-making functions with various relevant areas of law, the matrix provides a higher resolution approach to specific legal situations while retaining the clarity of bright line rules for each area.

Part I of this paper illustrates the diversity of legal approaches to adolescent autonomy and responsibility, showing inconsistencies in the legal limitations placed on adolescents' behaviors and the punishment for adolescents' transgressions. Part II explores the neuroscientific state of the art with respect to adolescent brain development. Part III maps this empirical data onto a few selected cases of adolescent behaviors of interest, exploring the relationship between brain development, behavior, and existing legal regulation. Part IV proposes the idea of a matrix that could help lawmakers evaluate whether or how to use neuroscientific information in conjunction with their assessments of other stakeholder and institutional

34 See, e.g., John Hagan et al., Ceremonial Justice: Crime and Punishment in a Loosely Coupled System, 58 Social ForCes 506, 510 (1979) (explaining the tension between judicial efficiency and individualized justice).

35 See, e.g., Planned Parenthood v. Casey, 505 U.S. 833, 844 (1992) (explaining that liberty cannot flourish without legal stability). 
interests, and normative and policy concerns, to create laws that are best designed to effectuate their intended purposes.

\section{LEGAL REgIMES CONSTRAINING ADOLESCENT AUTONOMY: A TYPOLOGY}

Legal treatment of adolescence varies across and within legal domains. This creates an unintuitive and often inconsistent framework for granting autonomy and attributing legal responsibility to adolescent actions. Recent Supreme Court opinions have turned to neuroscience to justify different punishments for juveniles than adults, for the same crimes. ${ }^{36}$ The Court has held that punishing juveniles equally to adults by imposing either the death penalty or life in prison without parole for nonhomicide crimes constitutes a violation of the Eight Amendment's prohibition on cruel and unusual punishment. ${ }^{37}$ Although the Supreme Court's jurisprudence on juvenile difference rests as much on evolving social norms as on neuroscientific findings, these recent opinions are exemplary in showing the ways in which social norms and scientific findings may interact to inform legal decision-making. ${ }^{38}$

\section{A. Recent Supreme Court Holdings Recognize Juvenile Developmental Difference}

In Roper v. Simmons, the Supreme Court held that imposing capital punishment on individuals who committed crimes as minors violates the Eighth Amendment prohibition of cruel and unusual punishments as applied to states by the Fourteenth Amendment. ${ }^{39}$ In the majority

36 See infra Part I.A. (discussing Roper v. Simmons and Graham v. Florida).

37 See infra note 39.

38 See infra Part I.A.

39543 U.S. 551 (2005) (overruling the prior standard that allowed for capital punishment for offenders sixteen years of age and older) (citing U.S. CONST. amend. VIII ("Excessive bail shall not be required, nor excessive fines imposed, nor cruel and unusual punishments inflicted.")). 
opinion, Justice Kennedy noted that Constitutional jurisprudence, rooted in "history, tradition, and precedent," must be balanced with "the evolving standards of decency that mark the progress of a maturing society." 40 Kennedy looked to the prevalence of states' rejection of the death penalty for juveniles to determine whether "our society views juveniles ... as categorically less culpable than the average criminal," 41 and found that most states had indeed rejected such capital punishment.42 Confirming this reasoning, Kennedy cited empirical findings linking youth with poor decision-making, recklessness, vulnerability to peer influence, and underdeveloped character, which together preclude juveniles from having the extraordinary moral culpability required for the death penalty. ${ }^{43}$ The amicus brief from the American Psychological Association stated that adolescence involves increased risk-taking and an undervaluation of future consequences, undermining traditional justifications for the death penalty. ${ }^{44}$ The opinion noted that moral responsibility does not simply emerge across the board at a particular age, but that drawing a bright line at age eighteen instead of sixteen would better accommodate the vulnerabilities of juveniles and align other areas of law that recognize adulthood at age eighteen. ${ }^{45}$

Picking up where Roper left off, the Supreme Court held in Graham v. Florida that, for non-homicide crimes committed when the offender was a minor, the sentence of life without parole likewise violates the Eighth Amendment. ${ }^{46}$ As in Roper, the Court in Graham first looked to "objective indicia of national consensus" on such

\footnotetext{
40 Id. at 560-61 (citation omitted).

41 Id. at 567 (citation omitted).

42 Id. at 568.

$43 \quad I d$. at 569 (explaining that the primary purposes of capital punishment, retribution and deterrence cannot justify the death penalty for juveniles as they can for adults).

44 Brief for the Am. Psychological Ass'n, and the Mo. Psychological Ass'n as Amici Curiae Supporting Respondent at 4-13, Roper v. Simmons, 543 U.S. 551 (2005) (No. 03-633), 2004 WL 1636447.

45 Roper, 543 U.S. at 574.

46560 U.S. 48,82 (2010).
} 
sentencing for juveniles and found a national consensus against it. ${ }^{47}$ Second, the Court turned to empirical evidence about the differences between juveniles and adults. This time, the Court relied more explicitly on the emerging neuroscientific data amici first put before the Court in Roper. 48 Validating its reliance on sociological and scientific studies in Roper, the Court found that "developments in psychology and brain science continue to show fundamental differences between juvenile and adult minds," such as a lack of fully-developed behavioral control and continuing character formation in juveniles. ${ }^{49}$ The Court also argued that, excluding homicide crimes, the severity of a crime committed by a juvenile cannot on its own establish the criminal's settled and confirmed "moral depravity" required for a punishment as harsh as life without parole. ${ }^{50}$ Because of the unique vulnerabilities of juveniles, the Court held that life without parole cannot be justified by any of the traditional purposes of criminal punishment-retribution, deterrence, incapacitation, and rehabilitation-and therefore the sentence constitutes cruel and unusual punishment. ${ }^{51}$

Roper and Graham illustrate the Supreme Court's recent translations of empirical evidence, including neuroscience, into normative legal standards. Such translations are not limited to the Supreme Court, nor are they limited to criminal law.

${ }^{47} I d$. at $62-66$.

48 Id. at 68 .

49 Id.

50 Id. at 69-70 (explaining that life without parole is "the second most severe penalty permitted by law," one that permanently deprives the convict of liberty, like the death penalty, without regard for the possibility of moral rehabilitation).

51 Id. at 71-74 (explaining that the case for retribution categorically diminishes for non-homicide crimes and for juveniles; that since juveniles are necessarily prone to rash decisions, they are unlikely-or even unable-to be deterred by harsh penalties; that juveniles are more capable of character development so they pose a lower risk of recidivism and need not be incapacitated for life; and that life without parole precludes the benefits of rehabilitation because the convict will never be allowed to reenter society). 


\section{B. A Typology of Legal Approaches to Adolescent Autonomy and Responsibility}

The law takes several approaches to differentiating the legal status of decisions made by adults from those made by juveniles. With respect to adolescents, approaches include total denials of autonomy, delegated autonomy, graduated recognition of autonomy, revocable autonomy, and total autonomy.

\section{Total Denials of Autonomy}

The legal category we describe as total denial of autonomy encompasses activities totally prohibited until the decision-maker reaches a certain age, often the age of majority. This means that the minor individual cannot engage in the activity, even with parental consent or under extraordinary circumstances. Some total denials of autonomy are uniform across the fifty states. Youth may not vote in federal elections until they reach age eighteen;52 some states and localities, however, establish a slightly lower minimum voting age for certain elections. ${ }^{53}$ In all fifty states, consistent with federal policy, persons under twenty-one may not buy alcohol. ${ }^{54}$ In all states, minors may not buy tobacco products. ${ }^{55}$ State practices vary more in other areas. In some states, minors categorically cannot get a tattoo, even with parental permission; in other states,

52 U.S. CONST. amend. XXVI. Note that this amendment prohibits the federal or state denial of suffrage to individuals eighteen and older, but states are permitted to establish lower voting ages.

53 See, e.g., Annys Shin, Takoma Park 16-Year-Old Savors His History-Making Moment at the Polls, The Washington Post (Nov. 3, 2013) http://www.washingtonpost.com/local/takoma-park-16-year-oldsavors-his-history-making-moment-at-the-polls/2013/11/03/89f00962425c-11e3-b028-de922d7a3f47_story.html.

54 See Consumer Information: Alcohol Laws by State, FED. Trade Comm'N (Sept. 2013), https://www.consumer.ftc.gov/articles/0388alcohol-laws-state.

55 See SLATI Overview Data, AM. LUNG Ass'N, http://www.lungusa2.org/slati/slatiOverview.php (last visited May 17, 2015). 
parental permission allows the minor to exercise limited autonomy in this area. ${ }^{56}$

Total denials of autonomy are not unique to legal regimes governing minors. The law categorically prohibits certain behaviors, even to fully competent adults. Most of these prohibitions relate to preventing harm to others: We are not free to injure, to force, to take without consent. 57 These prohibitions are basically other-regarding.58 A smaller category of prohibitions relates to limiting individuals' autonomy relative to their own bodies. ${ }^{59} \mathrm{We}$ are not free to consume illegal drugs, to sell our sexual services or parts of our bodies, or to consent to certain extreme forms of self-mutilation. ${ }^{60}$ Some private sexual behaviors remain illegal, even when engaged in by the proverbial "consenting adults." 61 The theoretical justification for these limitations is murkier and certainly is not unitary. Justifications for the prohibition of drug use and prostitution, for example, range from utilitarian considerations about the negative externalities of these behaviors on communities and societies, particularly the

56 See Tattoo and Body Piercing: State Laws, Statutes and Regulations, NAT'L CONFERENCE OF STATE LEG. (2009), http://www.ncsl.org/research/health/tattooing-and-body-piercing.aspx.

57 See, e.g., 1 SUBST. CRIM. L. $§ 1.2$ (2d ed.) (explaining the role of criminal law in prohibiting harmful conduct).

58 See, e.g., Bruce J. Winick, On Autonomy: Legal and Psychological Perspectives, 37 VILL. L. REV. 1705, 1713 (1992) (explaining how Mill's harm principle underlies and justifies other-regarding legal restrictions on autonomy).

59 See, e.g., Joel Feinberg, Legal Paternalism, 1 CANADiAn J. PHILOSOPHY 105, 105 (1971) ("The principle of legal paternalism justifies state coercion to protect individuals from self-inflicted harm, or in its extreme version, to guide them, whether they like it or not, toward their own good.").

60 See, e.g, Thaddeus Mason Pope, Is Public Health Paternalism Really Never Justified? A Response to Joel Feinberg, 30 OKLA. CITY U. L. REV. 121, 122 (2005) (exploring paternalism as a justification for restricting self-regarding behaviors).

61 See, e.g., Danielle Augustson \& Alyssa George, Prostitution and Sex Work, 16 GEO. J. GENDER \& L. 229, 230 (2015) (noting the illegality of consensual prostitution in most states). 
risks of violence and organized crime, ${ }^{62}$ to dignitary and paternalistic considerations. ${ }^{63}$ Prohibitions on certain private sexual behaviors, which, though antiquated, remain in many jurisdictions, are grounded in the notion of law as a form of public morality-and perhaps a residual sense of disgust. 64 These, though, are the minority: Legal denials of autonomy to adults primarily occur in those domains where harm to others not only would be likely but is the purpose of the action itself-like rape or battery. ${ }^{65}$ These, then, in contrast to the majority of legal regimes that deny autonomy to juveniles, reflect not a balancing of stakeholder interests, a utilitarian calculus, or paternalism, but the law's core public protective function.

\section{Delegated Autonomy}

In some domains, the law prohibits minors from engaging in certain behaviors that would be lawful for adults. Yet, rather than a total or categorical prohibition, it delegates to a parent or guardian the responsibility of authorizing the juvenile to engage in the action (or not). We call this category of laws "delegated autonomy," although it could also be conceived of as "delegated denials of autonomy." Delegated autonomy is common in the medical decision-making arena. Generally, adolescents cannot obtain medical care of even the simplest kinds without

62 See, e.g., James M. Cole, Guidance Regarding Marijuana Enforcement, Memorandum for all United States Attorneys, U.S. DEP'T OF JUSTICE 1-2 (Aug. 29, 2013) (listing federal priorities for enforcing marijuana prohibition, including sales to minors, criminal enterprises, diversion to prohibition states, pretext for trafficking other drugs, violence and firearms, drugged driving, cultivation on public lands, and use on federal property).

63 See, e.g., Kevin S. Toll, The Ninth Amendment and America's Unconstitutional War on Drugs, 84 U. DET. MERCy L. REV. 417, 443-44 (2007) (explaining and rejecting paternalistic and moralistic legal restrictions on autonomy with respect to drug use).

64 See Augustson \& George, supra note 61; see also Leon Kass, The Wisdom of Repugnance: Why We Should Ban the Cloning of Humans, 216 NEW REPUB. 17, 19 (1997) (arguing that disgust forms a valid basis for ethics and regulation).

65 See supra note 57. 
express authorization from a parent or guardian. ${ }^{66}$ Typically, a student cannot even get an aspirin or Tylenol from a school nurse without advance parental permission. ${ }^{67}$ In more medically serious situations, a minor cannot obtain treatment at a hospital emergency department without appropriate adult consent unless the medical need is so urgent that consent cannot be obtained in time to avoid a life-or-death situation. ${ }^{68}$ Nor can teens opt into voluntary medical procedures, such as cosmetic surgery. However, in all these cases, the adolescent can obtain the medical services-including cosmetic interventions-with the consent of the parent or guardian, a delegation of autonomy. ${ }^{69}$ And, adolescents retain some individual autonomy in this arena. Even though they cannot independently consent to medical treatment, they have the freedom to give or withhold their assent. ${ }^{70}$ Assent is willingness; if the adolescent is unwilling to go through with a treatment directed by or consented to by the parent or guardian, it can constitute a violation of medical ethics (if not law) for the medical professional to go forward over the adolescent's objections. ${ }^{71}$ Delegated autonomy regimes arise in a few areas apart from medical decision-making; a minor generally cannot marry but may, in some states, be

66 Minors and the Right to Consent to Health Care, 3 GuTTMACHER REPORT ON PUB. POLICY (2000), available at http://www.guttmacher.org/ pubs/tgr/03/4/gr030404.html.

67 See, e.g., School Health Services, ScH. Dist. OF Pickens Cty., available at http://www.pickens.k12.sc.us/Pages/Parents/Handbook/ School-Health-Services.aspx ("No aspirin and/or products containing aspirin will be given at school without physician and parent permission.").

68 See Minor Consent to Medical Treatment Laws, NAT'L Dist. ATTORNEYS Ass'N (Jan. 2013), http://www.ndaa.org/pdf /Minor\%20Consent\%20to\%20Medical\%20Treatment\%20\%282\%29.pdf.

69 See Plastic Surgery for Teenagers Briefing Paper, AM. Soc'y OF PlASTIC SURGEONS, available at http://www.plasticsurgery.org /news/briefing-papers/plastic-surgery-for-teenagers.html ("As with any surgery, parental consent is required for all plastic surgery procedures performed on teens younger than 18 years old.").

70 See Committee on Bioethics, Informed Consent, Parental Permission, and Assent in Pediatric Practice, 95 Pediatrics 314, 315 (1995).

71 See id. at 316. 
permitted to marry if he or she has parental consent..$^{72}$ Further, minors cannot join the military but may do so with the permission of a parent. ${ }^{73}$

\section{Graduated Autonomy}

Laws that operate on delegated autonomy require parental or guardian permission; they are binary, on/off regimes. Some laws relating to adolescents are less categorical; rather, they provide for gradual, or graduated, autonomy for minors. This approach permits teens to exercise partial autonomy and achieve full capacity based on age, without parental consent. Graduated autonomy regimes may be found in range of legal domains. Increasingly, states are experimenting with graduated autonomy regimes for licensure of drivers, permitting limited driving hours and distances to younger drivers and requiring adult supervision for early driving, then gradually-based on hours driven and the age of the driver-permitting full driving privileges. ${ }^{74}$ Similarly, teens can enter into employment without the consent of a parent or guardian, but the law retains a protective function by limiting the hours, types of work, and working conditions of minors. ${ }^{75}$ In the area of sexual relations, the law, too, provides for graduated autonomy. ${ }^{76}$ Sexual self-expression

72 See Teens/Minors Marriage License Laws, US MARRIAge LAWS (2014), http://www.usmarriagelaws.com/search/united_states /teen_marriage_laws/.

7310 U.S.C. $\S 505$ (2015).

74 See Graduated Driver Licensing (GDL) Laws, Governors HighwAY SAFETY ASS'N (May 2015), http://www.ghsa.org $/ \mathrm{html} /$ stateinfo/laws/license_laws.html.

75 See Child Labor Provisions for Nonagricultural Occupations Under the Fair Labor Standards Act, Child Labor Bulletin 101, WH1330, U.S. DeP'T LABOR WAGE \& Hour Div. (Feb. 2013), http://www.dol.gov/whd/regs/compliance/childlabor101.pdf.

76 In Indiana, for example, if one partner is underage, the law allows a defense to prosecution if the couple are in an ongoing relationship and not more than four years apart in age. See Ind. Code Ann. § 35-42-4-9. 
is a core area of autonomy and identity formation, ${ }^{77}$ yet can be fraught with risk. States vary considerably but the general trend is toward allowing adolescents the same autonomy to engage in sexual relations with each other that adults enjoy, but protecting them from sexual advances and potential sexual exploitation by adults. ${ }^{78}$ Hence, most states have statutory rape laws that criminalize adult sexual conduct with teens yet also have "Romeo and Juliet" exceptions that ensure sexual relationships between sameor similar-aged teens are not construed as criminal exploitation, or that teen-to-teen sexting is not charged as child pornography. ${ }^{79}$ We conceive of this as a "graduated autonomy" regime because it allows juveniles to experience their developing sexual autonomy in a limited or quasiprotected way while precluding certain sexual relationships that are more likely to be damaging or exploitative; in this way, it is somewhat analogous to graduated driving regimes.

It is difficult to identify a principled distinction between subject matters governed by delegated autonomy versus graduated autonomy regimes. In areas characterized by graduated autonomy, generally the activities governed are individually and socially beneficial but carry risks of various kinds and require the exercise of judgment. ${ }^{80}$ Accordingly, allowing young people to gain some experience while protecting them-and others-from the risks of unlimited autonomy seems reasonable. However, the same may be said of the activities typically governed by a delegated

77 See Lawrence v. Texas, 539 U.S. 558 (2003) ("Liberty presumes an autonomy of self that includes freedom of thought, belief, expression, and certain intimate conduct.").

78 See supra note 76.

79 See Summary of Current State Laws: Statutory Rape - Criminal Offenses, Assistant SEC'Y Planning \& Evaluation, DeP'T Health \& HUMAN SERV., http://aspe.hhs.gov/hsp/08/sr/statelaws/summary.shtml (last visited May 17, 2015).

80 Consider driving, a ubiquitous activity integral to autonomous decision-making and that connects individuals with society through recreational activities, education, and employment. Driving can have serious health consequences to the driver as well as third parties, but the importance of the activity warrants graduated autonomy. 
autonomy regime: Medical decision making and sexual decision making both fundamentally relate to the body of the young person in question, both require certain maturity and understanding of risks to self and others. Indeed, medical decision making may appear to be less likely to involve the risky and impulsive decision making almost inherent in sexual exploration. Holding aside problems of administrability, a principled argument could be made for switching these two regimes. We are not seriously advancing such a proposal, but we raise the point to highlight the lack of consistency that underlies many of the legal choices relating to the degrees of adolescent autonomy in particular contexts.

\section{Total Autonomy}

In some areas, the law provides adolescents with autonomy-at least front-end autonomy-equal to that enjoyed by adults, unrestricted by considerations of age or maturity. ${ }^{81}$ But this is not because, in these selected areas, youth are as mature as adults; rather, these categories consist of a heterogeneous set of practical and policy considerations that have led to isolated autonomy carveouts. These include, non-exhaustively, adolescents' ability to admit themselves without parental consent for medical treatment for substance misuse or mental health disorders; $; 2$ in some states, to obtain an abortion without parental or guardian notification or consent; 83 to obtain medical advice and services related to contraception; 84 to marry, if the female is pregnant. 85 Adolescents may also

81 "Front-end autonomy" refers to the fact that the law treats adolescents the same as adults with respect to taking particular actions, though it may later intervene to protect adolescents from, or punish them for, the consequences of those actions.

82 See supra note 66.

83 See State Policies in Brief: An Overview of Minors' Consent Law, GUTTMACHER INST. (May 1, 2015), http://www.guttmacher.org /statecenter/spibs/spib_OMCL.pdf

84 Id.

85 See Marriage Laws of the Fifty States, District of Columbia and Puerto Rico, CORNELl LEGAL INFORMATION INST., 
enter into contracts with the same front-end autonomy as adults but, as with adults who suffer from various forms of diminished capacity, may later revoke the contract. ${ }^{86}$

\section{Censure-Based Responsibility}

The criminal law embodies both a protective and a punitive attitude toward juveniles. ${ }^{87}$ The juvenile justice system is popularly believed to set up a continuum of responsibility based on age and the harm caused. 88 So, the younger the juvenile, the less responsible; the older the juvenile, the more responsible-a linear continuum on which responsibility increases gradually with age and maturity. In practice, however, various legislative efforts to respond to sensational-or sensationalized-cases of violence have led to a much harsher and less developmentally informed juvenile criminal system. 89

Despite historical efforts to establish a legal continuum of criminal responsibility, with lesser responsibility for younger individuals, contemporary state criminal law instead has a set of statutory rules that direct some juveniles into the adult system and others into the juvenile system, even where the juvenile offenders are the same age. ${ }^{90}$ The determinations generally are made on the basis

https://www.law.cornell.edu/wex/table_marriage (last visited Aug. 12, 2015).

86 See supra note 11.

87 See supra note 9.

88 See, e.g., Simona Ghetti \& Allison D. Redlich, Reactions to Youth Crime: Perceptions of Accountability and Competency, 19 BEHAV. SCI. LAW 33, 45 (2001) (finding that people perceive an increase in blameworthiness and accountability for criminal actions perpetrated by juveniles in accordance with their age).

89 See, e.g., Brenda Gordon, A Criminal's Justice or A Child's Injustice? Trends in the Waiver of Juvenile Court Jurisdiction and the Flaws in the Arizona Response, 41 ARIZ. L. REV. 193, 194 (1999) ("Nationally, state policymakers, responding to public outrage and fears about increasing juvenile crime, are advocating 'get tough' policies in an apparent attempt to incapacitate specific juvenile criminals and to deter violent juvenile crime.").

90 Juvenile Age of Jurisdiction And Transfer To Adult Courts, NAT'L Conference OF STATE LEg. (Oct. 1, 2014), 
of the harm the juvenile caused, not his or her age (much less his or her individual degree of maturity). ${ }^{91}$ The prevalence of adult penalties, and even incarceration in adult prisons for young adolescents, grew out of a tough on crime movement during the 1980 s that resulted in significant reform in juvenile law. ${ }^{92}$ The mantra of the day, driven by fear of a new generation of crack-baby "superpredators," was "adult time for adult crime." 93 Instead of a close examination of a particular juvenile's degree of maturity, criminal law generally looks to the external factor-the crime committed.

The reasoning that underlies these laws is that if a juvenile causes serious harm, then he or she is not truly a child but rather an adult-like criminal in a child's body. ${ }^{94}$ We call this "censure-based" responsibility because the degree of penalty and the form of punishment focus on the degree of censure that is appropriate to the harm itself, rather than to any determination about the personal culpability of the offender who caused the harm. These laws generally do not provide prosecutors or judges with the discretion to consider the alternative explanation: that the juvenile's actions, and the resulting harm, could flow from a flawed thought process characteristic of juveniles, such as not understanding risk, or not making good risk/reward calculations, or being unduly prone to poor decision-making in the peer context-much like the teens in the armpit-firehighway-rollover accident. 95 That case, which opened this article, is a perfect example of where stereotypically poor teen decision-making caused an accident—an accident that could have been charged as an adult crime if, through sheer

http://www.ncsl.org/research/civil-and-criminal-justice/juvenile-age-ofjurisdiction-and-transfer-to-adult-court-laws.aspx.

91 See supra note 9.

92 See supra note 18.

93 See Hudson, supra note 17.

94 See Gordon, supra note 89, at 225 (explaining that flawed systems treat juvenile offenders as "criminals who happen to be young, not children who happen to be criminals.") (quoting Alfred S. Regnery, Getting Away With Murder: Why the Juvenile Justice System Needs An Overhaul, 34 POL'Y REV. 65 (1985)).

95 See supra note 1. 
moral luck, the outcome had been worse than in fact it was. Given the uneven nature of juvenile development, we might ask whether such a continuum would be the appropriate way of accounting for juvenile difference in any event. We turn to this question in Parts III and IV, and instead propose that a matrix of considerations replace the model of the continuum.

\section{The Result-Multiple Regimes Lead to Inconsistent Outcomes}

These multiple regimes lead to legal outcomes that are internally inconsistent and even counterintuitive. In some ways, juveniles are entrusted with significant, even lifeand-death responsibilities. In other ways, they are denied basic autonomy in even minor decisions. A fifteen-year-old girl can legally work thirty hours a week at Wal-Mart, consent to sex with the same aged boyfriend, get married if pregnant, and check herself into drug rehab without parental consent. 96 With parental consent, she can get a nose job and breast implants. ${ }^{97}$ But she cannot get an aspirin at school without parental consent, 98 and she cannot vote, get a tattoo, drink, or smoke. ${ }^{99}$ In some jurisdictions, she cannot legally drive without an adult in the car. ${ }^{100}$ And yet, if her reckless driving kills somebody, she can be waived into the adult criminal justice system and be sentenced as an adult to decades in prison. ${ }^{101}$

Do these different legal regimes make any sense or do they just comprise a historically contingent pastiche? In Parts III and IV, we argue that it is bit of both: Some of these legal choices about the degree of autonomy to grant, or responsibility to impose upon, adolescents make more sense, both as a matter of law and of developmental biology, than they seem to on the surface-while others fly in the

\footnotetext{
96 See supra Part I.B.

97 See supra note 69.

98 See supra note 67.

99 See supra notes 52, 56; see 21 U.S.C. $§ 387 f$.

100 See supra note 74.

101 See supra Part I.B.5.
} 
face of the principles of both sets of systems. The disparate legal approaches to adolescent decision making may be perfectly appropriate in certain circumstances. But they also may produce peculiar and inconsistent results. Not only do some of the conflicts in legal regimes that govern and constrain juvenile behavior appear to be counterintuitive, they do not accord with the psychological and biological differences between juveniles and adults. Increasing understanding of the brain may now enable more sophisticated consideration of the relationships between the biology of adolescence and the law's normative underpinnings and policy goals.

\section{HOW - AND WHY - ADOLESCENTS ARE DIFFERENT}

\section{A. The Brain's Adolescence}

The adolescent brain has pronounced strengths and weaknesses. ${ }^{102}$ To the extent that there is validity to the idea of general intelligence, or " $g$," teens are as smart as they ever will be. ${ }^{103}$ General intelligence measures of performance on tasks such as cognitive speed and the ability to coordinate cognitive and motor performance increase through adolescence, peak at about age twentyfour-the exact age at which the brain is said to be "adult" and "mature"-and decline from there.104 In important ways, late adolescents are mental athletes who are at their peak. ${ }^{105}$ Colloquially, we may say that teens are "dumb" but they most assuredly are not—or at least not more dumb

102 For an excellent overview of adolescent brain development, see generally Ronald E. Dahl, Adolescent Brain Development: Vulnerabilities and Opportunities, 1021 ANNALS N.Y. ACAD. SCIENCES 1 (2004).

103 See Gottfredson, supra note 23.

104 See Joseph J. Thompson et al., Over the Hill at 24: Persistent Age-Related Cognitive-Motor Decline in Reaction Times in an Ecologically Valid Video Game Task Begins in Early Adulthood, 9 PLOS ONE e94215 (2014).

105 See J.P. Rushton \& C.D. Ankney, Whole Brain Size and General Mental Ability: A Review, 119 InT. J. NeuroscI. 692-732 (2009) (showing that adult brains shrink about two grams per year and lose corresponding degrees of function). 
on average than adults. When we say that teens are "dumb," what we mean is: They predictably do dumb things. ${ }^{106}$ They take bad risks and make bad bets. ${ }^{107}$ They engage in actions for the wrong reasons, and to impress the wrong people.108 And, when making decisions, they frequently fail to bring to bear relevant facts or information that they already know-but that they cannot seem to make use of in the moment. 109 This juxtaposition of ordinary, adequate intelligence and sub-par decision making indicates a disconnect. Indeed, there are literal disconnects: As different regions of the adolescent brain mature at different rates, and develop connections to each other only during and through the maturation process, it is possible for an adolescent to know something with one part of his or her brain but not with another-or to be less able than an adult to mediate between conflicting mental processes and arrive at an integrated decision. 110 In particular, adolescents suffer relative to adults in their capacities to assess what is a good versus a bad risk, to inhibit impulses, and to silence the inner roar of concerns about what their peers think of them. ${ }^{111}$ This short section will first define adolescence and then look at the developmental neuroscience findings that help explain these deficits.

"Adolescence" denotes the time between childhood and adulthood, typically defined as beginning with the

106 See, e.g., supra note 1.

107 See Leah H. Somerville \& B. J. Casey, Developmental Neurobiology of Cognitive Control and Motivational Systems, 20 CURREnt OPINION In NeUROBIOLOGy 236, 236 (2010).

108 See Leah H. Somerville et al., The Medial Prefrontal Cortex and the Emergence of Self-Conscious Emotion in Adolescence, 24 PSYCHOLOGICAL SCIENCE 1554, 1554 (2013) (explaining the neurological role of peer influence on adolescent decision making).

109 See Somerville \& Casey, supra note 107, at 237 (describing how adolescents overvalue immediate rewards to the detriment of goaloriented behavior).

110 See Steinberg, supra note 29 (explaining that the adult brain distributes decision making process across multiple structures, integrating such functions as risk evaluation and planning ahead, whereas in adolescents, "[i]t's as if the brain's accelerator is pressed to the floor before a good braking system is in place.").

111 See generally Somerville \& Casey, supra note 107. 
physiological onset of puberty, between ages eleven and thirteen, and ending with early adulthood, by or before age twenty-four. ${ }^{112}$ These physical changes correlate with the acquisition of new responsibilities and social roles, placing adolescents in the midst of a struggle to form their identities while managing peer pressure and heightened emotional reactivity - a characteristic recipe for risky behavior and "sensation seeking." 113 In addition to these social and cultural changes, adolescents experience rapid physical changes from growth spurts to hormone swells.114 Adolescents thus inhabit a cacophony of physical transformation, social experimentation, and expansion of responsibilities, a sensitive period for social and identity formation. ${ }^{115}$

Spurred by the onset of puberty typically around age eleven or twelve for girls and twelve to thirteen for boys, secondary sexual characteristics and reproductive capacity develop, largely initiated by the release of hormones from the hypothalamus and pituitary gland. ${ }^{116}$ The brain's overall size has already peaked a year or two before puberty begins, ${ }^{117}$ but maturity comes with the selective pruning of unneeded brain connections and the strengthening of the remaining connections among brain regions throughout adolescence. ${ }^{118}$

112 See, e.g., Pfeifer \& Blakemore, supra note 20 , at 1 ; see also Thompson et al., supra note 104 (establishing 24 as the age of neurological adulthood). What constitutes "adulthood" is not exactly clear, and can refer to the maturation of physiological and psychological capacities for independence and self-regulation, a legal determination of adulthood, and/or a cultural affirmation of adulthood.

113 See Leah H. Somerville et al., A Time of Change: Behavioral and Neural Correlates of Adolescent Sensitivity to Appetitive and Aversive Environmental Cues, 72 BRAIN AND Cognition 124, 125 (2010).

114 See, e.g., Pfeifer \& Blakemore, supra note 20, at 3.

115 See generally id.

116 See, e.g., Puberty, The Patient Educ. Inst., Inc. (2012), available at http://online.mufasser.com/modules_v3/ peditrcs/pdfp01a1/pdfp0101/pdfp0101.pdf.

117 See Jay N. Geidd, The Teen Brain: Insights from Neuroimaging, 42 J. AdOlEsCENT HEALTH 335, 336 (2008).

118 See B.J. Casey et al., The Adolescent Brain, 28 Developmental REVIEW 62, 67 (2008). 
Along with social and physical changes, the adolescent brain undergoes significant structural and functional transformations. Animal studies demonstrate that puberty catalyzes a spike in axon and synapse production, ultimately pruned back late in adolescence. ${ }^{119}$ Fiber density between the amygdala and prefrontal cortex (PFC) continues to increase into the early stages of adulthood. ${ }^{120}$ White matter accrues through adolescence and into early adulthood, caused by myelination, the insulation of fibers with cholesterol, which improves their electrical efficiency. ${ }^{121}$ Pruning removes unnecessary neurological connections, and persists throughout adolescence more significantly in the PFC than the accumbens, suggesting an earlier maturation of the accumbens. ${ }^{122}$ The increased development and interconnection among these brain regions temporally correlates with the new roles, interests, and responsibilities of adolescents, but the brain's uneven maturation renders adolescents somewhat unequipped to handle these experiences.

In addition to these structural changes, adolescence involves changes to neurotransmitter systems in both cortical and subcortical areas of the brain. ${ }^{123}$ Dopamine regulates excitatory and inhibitory communications among the accumbens, amygdala, and PFC and its expression peaks differentially in these areas over time. ${ }^{124}$ Dopamine receptors proliferate along the pathways connecting the limbic systems and the PFC more early in adolescence than

\footnotetext{
119 See id. at 336-37.

120 See Somerville et al., supra note 113, at 128.

121 Vincent J. Schmithorst \& Weihong Yuan, White Matter Development During Adolescence as Shown by Diffusion MRI, 72 BRAIN \& CoGNITION 16, 16-25 (2010).

122 See Somerville et al., supra note 113, at 127.

123 See B.J. Casey et al., The Adolescent Brain, 1124 Annals N.Y. ACAD. SCIENCES 111, 113 (2008).

124 Id. ("Dopamine projections to the prefrontal cortex continue to develop into early adulthood, with dopamine levels peaking in the prefrontal cortex during adolescence versus earlier or later in life in nonhuman primates and in rats. Dopamine receptor expression is highest in the accumbens during early adolescence.").
} 
later on. ${ }^{125}$ This evidence produces a complex map of structural, connective, and communicative changes involving subcortical and cortical areas of the brain, which can help shed light on the formative years of adolescence. ${ }^{126}$

Verifying this data in human studies involves the use of magnetic resonance imaging (MRI) technologies such as structural MRI, diffusion tensor imaging (DTI), and functional MRI. ${ }^{127}$ These devices enable scientists to study neurological structures and connections, as well as the realtime functioning of subjects' brains as subjects perform various tasks or respond to stimuli. ${ }^{128}$ MRI studies have produced important data about the size and composition of brain regions during development. The prefrontal cortex takes a particularly long time to mature, and the subcortical basal ganglia undergo significant changes. ${ }^{129}$ These subcortical ganglia are implicated in numerous functions, but for purposes of understanding adolescent behavior, we can focus on their role in behavior selection (e.g., "between these several options, what would be the right thing to do now?") 130 and cognitive coordination ("I have several different thoughts and impulses. How do I align my thoughts, feelings, and behaviors at this moment?").131 Michael Gazzaniga, the founder of the field of cognitive neuroscience, has called the PFC the seat of "free won't"because of its role in overriding emotional impulses. ${ }^{132}$ Related executive functions include planning, sequencing, organization, inhibition, problem solving, and behavior

125 See Adriana Galvan, Adolescent Development of the Reward System, 4 Frontiers in Human Neuroscience 1, 2 (2010).

126 See Casey et al., supra note 123 , at 114 .

127 See Casey et al., supra note 118, at 65.

128 See id. at 65-70.

129 See Casey et al., supra note 123, at 114.

130 V.S. Chakravarthy et al., What Do the Basal Ganglia Do? A Modeling Perspective, 103 BIOLOGICAL CYBERnETICS 237, 244-49 (2010).

131 Andrea Stocco et al., Conditional Routing of Information to the Cortex: A Model of the Basal Ganglia's Role in Cognitive Coordination, 117 PsYCHOL. REV. 541 (2010).

132 See Michael S. Gazzaniga, The Ethical Brain: The Science OF OUR Moral Dilemmas 95-96 (2006). 
control, ${ }^{133}$ and can be measured with neuropsychological tests, such as the go/no-go task of inhibitory control. ${ }^{134}$ The relatively late development of the PFC and maturation of its connections to impulse-generating and emotion-generating regions of the brain may help explain the relative impulsivity and risk-preferring nature of adolescents-even when they "know better." 135

DTI shows promise in providing a finer grained analysis of how the brain strengthens some connections and prunes back others. ${ }^{136}$ White matter connections between the PFC and other areas have been associated with working memory and impulse control. ${ }^{137}$ Again, connections among different areas develop at different rates and times during adolescence. 138 Enabling researchers to look at function in addition to structure, fMRI studies have confirmed the role of the PFC in the development of cognitive control and decision-making. ${ }^{139}$ Task performance studies show that adult brains specialize particular prefrontal regions for certain tasks, whereas children's prefrontal areas function more diffusely, suggesting that neurological development involves both changes within brain regions and among their connections. ${ }^{140}$

133 See, e.g., Akira Miyake et al., The Unity and Diversity of Executive Functions and Their Contributions to Complex "Frontal Lobe" Tasks: A Latent Variable Analysis, 41 Cognitive Psychology 49, 53-59 (2000).

134 See, e.g., Kurt P. Schulz et al., Does the Emotional Go/No-Go Task Really Measure Behavioral Inhibition? Convergence with Measures on a Non-Emotional Analog, 22 ARCHIVES OF ClinICAL NEUROPSYCHOLOGY 151(2007) (supporting the incorporation of emotionally-salient stimuli into a traditional behavioral inhibition test).

135 See Casey et al., supra note 123, at 116-17.

136 Id. at 115.

137 Id. (noting that prefrontal-parietal connections pertain to working memory and prefrontal-basal ganglia connections correlate with impulse control).

138 Id. at $116-17$.

139 Id. at 115.

140 Id. (referring to "flanker, Stroop, and go/no-go" tasks). 


\section{B. Developmental Disparity Between PFC and Limbic System}

Adapting to new roles and responsibilities, adolescents navigate unfamiliar territory by trial and error, seeking novelty, excitement, and reward.141 This often manifests itself as risky behavior as adolescents develop an experiential base to understand their newfound impulses and relationships. ${ }^{142}$ Uneven and disparate neurological development underlies these suboptimal behaviors. Prefrontal regions of the brain, which enable executive functions such as "top down," inhibitory control over impulses, develop along with white matter at a relatively even, linear rate throughout adolescence. ${ }^{143}$ By correlating a steady increase in performance on impulse control tasks, such as resisting immediate rewards, with prefrontal brain regions of increasingly aged subjects, scientists have theorized that the development of top-down neurological control of impulses follows a linear trajectory. ${ }^{144}$ This means that not only do the prefrontal regions themselves develop slowly, but that their long-range connections to other parts of the brain develop slowly as well, and the cognitive capacities they facilitate do not mature until late in adolescence. ${ }^{145}$

By contrast, the subcortical regions, including the amygdala, hippocampus, and thalamus-correlated with emotion, motivation, and reward-develop rapidly during early adolescence in terms of both structure and function, outpacing the slower maturation of the prefrontal regions. ${ }^{146}$ Since interactions between the cortex and subcortical regions play a major role in producing behavior, the disparity between the emotional and intellectual

141 See, e.g., Galvan, supra note 125 , at 6-7.

142 Id.

143 See B.J. Casey et al., The Storm and Stress of Adolescence: Insights from Human Imaging and Mouse Genetics, 52 DEVELOPMENTAL PSYCHOBIOLOGY 225, 226 (2010).

144 See Somerville \& Casey, supra note 21, at 238.

145 Id. at 239.

146 See B.J. Casey et al., Braking and Accelerating of the Adolescent Brain, 21 J. RESEARCH ON ADOLESCENCE 21, 22 (2011). 
components of decision making create various decisionmaking biases and vulnerabilities. ${ }^{147}$

\section{Emotional Control and Reactivity}

Manifesting itself as an overvaluation of emotional information, this developmental disparity often leads to poor decisions when emotional and intellectual evaluations conflict. ${ }^{148}$ An adolescent may "know better" than to take a particular, emotionally salient course of action, but poor cognitive control biases the individual in favor of emotional reactivity. ${ }^{149}$ With an insufficiently developed capacity for "free won't," adolescents have trouble inhibiting impulsive, risky, or aggressive inclinations. ${ }^{150}$ Logical calculations of risk and reward take a back seat to emotional significance and immediate reward.151 This may be related to weak connections between emotional processing regions of the brain and more cognitive, intellectual regions. It may also be related to heightened activity in the nucleus accumbens, a brain region associated with reward processing.

The amygdala assigns emotional significance to information determined to be salient, prioritizing it for translation into behavior. ${ }^{152}$ The amygdalae of adolescents tend to show larger responses than in adults and correlate with a poor ability to control emotional responses related to

147 Id.

$148 \quad I d$. at 22 ("[I]n emotionally salient situations, subcortical systems will win out (accelerator) over control systems (brakes) given their maturity relative to the prefrontal control system.").

149 See Casey et al., supra note 123, at 116-17 ("[W]hen a poor decision is made in an emotional context, the adolescent may know better, but the salience of the emotional context biases his or her behavior in opposite direction of the optimal action.").

150 See id. at 112.

151 See id.

152 See Geidd, supra note 117, at 338; see also Somerville et al., supra note 113 , at 126 ("The amygdaloid complex, a cluster of nuclei situated in the medial temporal lobe, plays a critical role in processing information of biological significance, including emotionally evocative stimuli, potential threats, and cues depicting the emotional states of others."). 
aggressive behaviors and mood problems. ${ }^{153}$ Prefrontal areas regulate this process based on environmental feedback. ${ }^{154}$

A major antecedent of adolescent emotional reactivity lies in the individual's emergent task of fitting into new social groups. ${ }^{155}$ As children enter adolescence, they develop new social roles and experience heightened sensitivity to peer approval. ${ }^{156}$ fMRI studies of adolescents engaged in the game of "cyberball," simulating experiences of social inclusion and exclusion, show that the ventral anterior cingulate cortex and insula respond to exclusion and that the ventrolateral PFC activates less in adolescents than adults. ${ }^{157}$ Another task simulating internet chatting demonstrated insula activation during acceptance, not rejection, suggests that the number of peers involved and the subject's interest in the approval of each of those peers, affects the neurological response to acceptance or rejection. ${ }^{158}$ These and other studies of peer influence show that social acceptance and rejection implicate affective responses in the brain, significantly affecting adolescent decision-making by playing into their characteristic overvaluation of affective information. ${ }^{159}$

153 See Somerville et al., supra note 113, at 125 (“[A]dolescents' negative emotional states are not only frequent but their emotional responses also tend to be more intense, variable and subject to extremes relative to adults.").

154 See Derek G.V. Mitchell, The Nexus Between Decision Making and Emotion Regulation: A Review of Convergent Neurocognitive Substrates, 217 BeHAVIOURAL BRAIN RESEARCH 215, 226 (2011) ("[C]ommon functional computations underlie adaptive decision making and emotional regulation; furthermore, these computations are likely governed by overlapping areas of prefrontal cortex.").

155 Leah H. Somerville, The Teenage Brain: Sensitivity to Social Evaluation, 22 CURRent DiReCtions IN Psychological Science 121, 121 (2011).

156 See Pfeifer \& Blakemore, supra note 20, at 5-6 ("Compared with children, adolescents are more sociable, form more complex and hierarchical peer relationships and are more sensitive to acceptance and rejection by peers.").

157 Id. at 6.

158 Id.

159 Id. at 7 ("[Peer interactions of various types are highly likely to arouse an affective response in adolescents...."). 
None of this is to suggest that emotion only contributes negatively to decision-making. The constructionist approach to neurobiological psychology holds that emotion and rational cognition are both types of attention, each with a proper role in decision-making. ${ }^{160}$

\section{Reward and Impulsivity}

The lack of prefrontal development in combination with heightened limbic activity (specifically in the accumbens) correlates with an overvaluation of rewards and short-term gains. ${ }^{161}$ Scientists differ on how to model adolescents' uniquely impaired processing of incentives: some suggest that an under-recruitment of relevant brain regions renders modest rewards unappealing, leading adolescents to be disproportionately motivated by expectations and desires of high reward. ${ }^{162}$ Others believe that neurological overactivity inflates sensitivity to reward, causing adolescents to seek novelty and sensation. ${ }^{163}$ Some studies suggest that these models may be reconciled by noting that they correlate with different phases of reward processing. The under-activity model emerged from studies of anticipating rewards, whereas the over-activity model correlates with receiving rewards. ${ }^{164}$ Reward overvaluation can also be modeled interconnectively; the "triadic" model suggests that limitations in prefrontal executive control and amygdalamediated harm avoidance allow the overactive ventral striatum to control the translation of overvalued incentives into behavior. ${ }^{165}$

160 Kristen A. Lundquist et al., The Brain Basis of Emotion: A MetaAnalytic Review, 35 BeHAVIORAL AND BRAIN SCI. 121, 142 (2012) (discussing the constructionist approach to emotion, which holds that "affect, conceptualization, and executive attention (and perhaps other psychological operations) cooperate to realize a behavioral outcome.").

161 See Somerville \& Casey, supra note 21, at 237.

162 See Galvan, supra note 125, at 1.

163 Id.

164 See Charles Geier \& Beatriz Luna, The Maturation of Incentive Processing and Cognitive Control, 93 Pharmacological Biochemistry AND BEHAVIOR 212, 218 (2009).

165 Id. at 213. 
A similar model holds that underdeveloped aspects of cognitive control, such as inhibition and working memory, combine with reward overvaluation to result in risky behavior. ${ }^{166}$ Response inhibition enables individuals to consider behavioral alternatives and choose appropriate actions; deficiencies in this system can bias a decisionmaker in favor of short-term gains. 167 Concomitant deficiencies in working memory hinder comparisons of incentive information associated with multiple alternatives. ${ }^{168}$ In other words, a certain amount of cognitive control is required to process and compare expected features of different behavioral options, such as estimations of reward value, the likelihood of actually getting the reward, and one's experiential history related to that reward. ${ }^{169}$ Importantly, studies show that adolescents are not necessarily bad at evaluating the risks of behaviors, but they have trouble integrating that information with other salient factors, which may be overvalued themselves, such as peer influence and affective information. ${ }^{170}$

The developmental lacuna between prefrontal and limbic systems represents not only the evolutionary process of seeking novelty, pleasure, and independence, but also an imbalance between these emotional, short-sighted adolescent drives and the "self-regulatory competence" expected of adults. ${ }^{171}$

\section{THREe CASES OF JUVENILE LAW ANALYZED VIA NEURODEVELOPMENTAL CRITERIA}

Adolescents are not uniformly disadvantaged relative to adults. Some legally relevant contexts play into these

$166 I d$. at $217-18$.

167 Id. at 217.

168 Id. at $217-18$.

169 Id.

170 Kerstin Konrad et al., Brain Development During Adolescence: Neuroscientific Insights into This Developmental Period, 110 DEUTSCHEs ÄRZTEBLATT INT'L 425, 428 (2013).

171 See Somerville et al., supra note 113 (quoting Laurence Steinberg, Risk Taking in Adolescence: What Changes, and Why?, ANNALS N.Y. ACAD. SCI. 51 (2004)). 
disadvantages and vulnerabilities, to greater or lesser extents, while others do not. Surges in novelty-seeking behavior and sensitivity to peer influence, combined with the slower maturation of impulse control, lead to characteristically emotional decision-making and poor risk/reward evaluations. ${ }^{172}$ With this knowledge in hand, policymakers can have a more accurate starting point to map the particular vulnerabilities of adolescents onto legally significant behaviors. This can inform in more nuanced and precise ways the analysis of where the law ought, or ought not, to limit the autonomy it extends and the responsibility it imposes on adolescents.

This Part will examine three cases relating specifically to adolescents: the case of tattooing; the case of alcohol and tobacco regulation; and the case of criminal responsibility for intentional violence. It will then evaluate those topics in light of juvenile developmental neuroscience, the interests of other stakeholders, and the institutional considerations that frame them. The purpose is to use these cases as models for how lawmakers might analyze juvenile developmental neuroscience in behavioral, legal, and social context to inform lawmaking. The conclusions of these case studies inform the proposal that we make, for a formalized analytical matrix, in Part IV.

\section{A. The Case of Tattooing}

Tattooing presents an interesting case relative to the regulation of adolescent behavior. It seems serious and unserious at the same time. On the one hand, a tattoo is a life-long commitment. 173 On the other hand, it is just body art; unlike drinking, driving, or using drugs, tattoos carry little to no risk of harming or killing oneself, and no such

172 See supra Part II.

173 See, e.g., Olga Khazan, The Secret to a Tattoo's Permanence: The Immune System, The AtLantic Health (July 22, 2014), http://www.theatlantic.com/health/archive/2014/07/the-real-reasontattoos-are-permanent/374825/ (explaining why tattoos last a lifetime). 
risk to others. ${ }^{174}$ Does it make sense to have an absolute prohibition against adolescent tattooing, while permitting adolescents to check themselves into a drug treatment center or obtain an abortion-decisions that seem more momentous and weighty? Examining the case of tattooing, it seems that the law makes sense on one view of what it is that law is supposed to do. But a closer examination shows that, despite the unfortunate relationship between tattooing and adolescent vulnerabilities in decision making, various extra-neuroscientific factors, including legal norms, social norms, and institutional considerations, must combine with judgments about adolescents to justify legal regimes relating to the practice. Neurodevelopmental biology suggests that teens may need to be protected from making a bad decision relative to this activity more than relative to other kinds of activities, but the enactment of a legal prohibition still rests on a sort of aesthetic paternalism, a social choice that is certainly contestable and not required by particular scientific findings. ${ }^{175}$

Tattooing seems to fit in with all major forms of adolescent psycho-social difference. Tattooing is often related to significant peer influence. ${ }^{176}$ One need only look at the massively increased popularity of tattoos in the last

174 But see Think Before You Ink: Are Tattoos Safe?, FDA CONSUMER HEALTH INFORMATION (October 2009), http://www.fda.gov/downloads/ForConsumers/ConsumerUpdates/UCM1 43401.pdf (explaining that tattoo needles and inks carry some risk of infection, allergic reaction, scarring, granulomas, and MRI complications).

175 See Feinberg, supra note 59, at 116 ("The state might even be justified in using its taxing, regulatory, and persuasive powers to make [a potentially risky activity] more difficult or less attractive; but to prohibit it outright for everyone would be to tell the voluntary risk-taker that even his informed judgments of what is worthwhile are less reasonable than those of the state, and that therefore, he may not act on them.... As a principle of public policy, it has an acrid moral flavor, and creates serious risks of governmental tyranny."). Query, however, whether adolescent neurological vulnerabilities justify a paternalistic approach. Are teens-subject to their limited decision making capacities - voluntary risk-takers making informed judgments?

176 See, e.g., Alden E. Roberts \& Jerome R. Koch, Correlates of Tattoos and Reference Groups, 99 PsycholoGiCAL REPoRTs 933 (2006). 
decade to see that, since it is socially acceptable or even desirable, more people do it. ${ }^{177}$ Despite its popularity, it remains perceived as a risky or transgressive thing to do, because it can be accepted by one's peer group but frowned upon by one's parents' generation; thus, it can mark both fitting in and rebelling, an irresistible combination for teen identity formation. ${ }^{178}$ It is also a sensation-seeking activity, as one might wonder what it feels like to get a tattoo or to walk around having one.179 And it may be the product of extreme temporal discounting: "I love this so much now that I cannot imagine being unhappy with it in the future. I will always want my favorite band's name tattooed on my face." 180

Given tattooing's remarkable fit with each of the major vulnerabilities in average adolescent decision making, does this suggest that laws categorically barring juveniles from obtaining tattoos (even with parental consent), are blessed by biology? Can we derive the right legal regime relative to tattoos from this analysis of the relationship between juvenile developmental biology and the social signification of the practice of tattooing?

Not quite: Whether there is a role for the legal regulation of this behavior still depends on a normative account of what the law is supposed to do. Barring tattooing is paternalistic and limits autonomy. Tattooing does not have any significant negative externalities. If an individual gets a stupid tattoo, he or she alone suffers; it is not like drinking and driving, which presents significant risk to others. We might also ask whether the type of harm that an individual suffers from getting a regretted tattoo is the kind of harm from which the law is supposed to protect individuals. The kind of harm here is not like the harm of smoking, which can lead to disease and death, or the harm of unsupervised driving, which can lead to the deaths of

177 See, e.g., Samantha Braverman, One in Five U.S. Adults Now Has a Tattoo, THE HARRIS POLL (Feb. 23, 2012).

178 See id. (showing that despite the increasing prevalence of tattoos, they are still largely seen as a sign of rebelliousness).

179 See Somerville et al., supra note 113.

180 See Geier \& Luna, supra note 164, at 217. 
others. Here, the harms (if any) are emotional and aesthetic.

Ought the law to be engaging in aesthetic paternalism? If so, should the law, on the same grounds, require a fortyeight-hour waiting period before a teen can get an unfortunate but trendy hair cut? If the aim of the laws categorically barring tattoos is to save juveniles from the long-term emotional regret of a bad decision, then should the law require that teens, e.g., receive judicial permission before breaking up with that really nice boy or girl who may be "the one"? On a libertarian view of the law, we could say "why is it a matter of concern for the state if somebody gets a horrible tattoo at seventeen that affects his or her professional and romantic prospects?" The law's paternalism toward adolescents is the only justification for this legal regime. ${ }^{181}$ One might object that an adolescent deciding to get a tattoo interferes with the parent's rights over the adolescent; 182 but in that case, if the parent is the stakeholder whom the law aims to protect, the appropriate legal regime would be to permit tattoos with parental consent-or to allow parents to tattoo their children even without the child's assent, which is prohibited. Calling the law paternalistic not is intended to be pejorative here; we merely are making clear the role that the law is playing relative to adolescents in this context.

In the case of tattooing, even though it implicates every teen vulnerability, there is no necessary outcome for the law. The law does tell us, though, that if we are concerned about the kinds of problems that do activate teen decisionmaking vulnerabilities and that have long-term negative consequences (even if emotional or aesthetic), then these are the kinds of features of a decision where law may have a case for getting involved. If one believes that there is an

181 See Hodgson v. Minnesota, 497 U.S. 417, 444 (1990) ("The State has a strong and legitimate interest in the welfare of its young citizens, whose immaturity, inexperience, and lack of judgment may sometimes impair their ability to exercise their rights wisely.").

182 Wisconsin v. Yoder, 406 U.S. 205, 232-33 (1972) (explaining the traditional and fundamental right of parents to direct the upbringing of their children). 
appropriate role for some graduated autonomy in the law, even in areas where there are no significant externalities, tattooing would be the paradigmatic example.

\section{B. The Case of Alcohol, Tobacco, and Other Addictive Substances}

Just like getting a tattoo, vulnerability to misuse of alcohol, tobacco, and drugs of abuse arises from the combination of impulsivity, novelty- and sensation-seeking, overvaluation of affective information, and peer influence. ${ }^{183}$ The misuse of these substances can have particularly negative consequences on the developing brain. ${ }^{184}$ And, unlike tattooing, teens' misuse of these substances and potential addiction to them can result in life-long harm or even death to the individual, and may lead to the deaths of others. ${ }^{185}$ Thus, legal regimes that intend to consider the relationship between developmental neurobiology and the subject of regulation should attend to these factors in designing regulatory regimes. Indeed, tobacco regulation has been a model in this area: Following tobacco companies' own insights that addicting children and young adolescents creates life-long customers, regulators have aggressively worked to limit juvenile access to all tobacco products. 186

Adolescence is itself a risk factor for the use of tobacco, alcohol, and drugs of abuse, and for the development of

183 See supra Part II; see also Sunita Bava \& Susan F. Tapert, Adolescent Brain Development and the Risk for Alcohol and Other Drug Problems, 20 Neuropsychol. Rev. 398, 403 (2010) (finding that the "[p]redilection for risk-taking and sensation seeking during adolescence is associated with increased substance use and the potential for longterm health problems.").

184 See Bava \& Tapert, supra note 183, at 403-06 (explaining that adolescent substance use has detrimental effects on the brain's structure and function, affecting cognitive capacities related to "attention, speeded information processing, spatial skills, learning and memory, and complex behaviors ....").

185 See Bharath Chakravarthy et al., Adolescent Drug Abuse Awareness \& Prevention, 137 InDIAN J. MED. REs. 1021, 1021 (2013).

186 See, e.g., 21 C.F.R. $§ 1140$ (2014) (prohibiting the sale and distribution of tobacco products to persons younger than 18). 
dependencies thereon. ${ }^{187}$ During the teen years, there is a sharp escalation in the use of alcohol, the most prevalent intoxicant. ${ }^{188}$ Rates of substance use also jump in the early teen years and rise dramatically throughout adolescence. 189 These behaviors provide substantial short-term rewards at the expense of long-term risks, implicating adolescents' overvaluation of immediacy, pleasure, and recent experience relative to their limited ability to consider their future selves or the long-term implications that their actions may have on others. ${ }^{190}$ Further, "[m] ost risky behaviors in humans-including alcohol abuse-occur in social situations," implicating adolescents' susceptibility to peer influence. ${ }^{191}$ Adolescents are not the only people who use alcohol as a social lubricant, of course, or who leverage its well-known power to make one feel less awkward or to make others seem more interesting. ${ }^{192}$ However, adolescence is a "sensitive period" for social development, in which teens learn how to be social in the ways of their own

187 See B. J. Casey \& Rebecca M. Jones, Neurobiology of the Adolescent Brain and Behavior: Implications for Substance Use Disorders, 49 J. AM. ACAD. ChILD \& AdOLEscent Psychiatry 1189, 1197 (2010) ("This imbalance between these developing systems [rapidly developing "bottom-up" motivational systems and slowly maturing "topdown" cognitive control systems] during adolescence may lead to heightened vulnerability to risk-taking behaviors and an increased susceptibility to the motivational properties of substances of abuse."); see also Substance Abuse and Mental Health Services Administration, Results from the 2012 National Survey on Drug Use and Health: Summary of National Findings, SAMHSA.gOV (Sept. 2013), http://www.samhsa.gov/data/NSDUH/2012SummNatFindDetTables/Nat ionalFindings/NSDUHresults2012.pdf.

188 See Bava \& Tapert, supra note 183, at 403.

189 See id.

190 Valerie F. Reyna \& Frank Farley, Risk and Rationality in Adolescent Decision Making: Implications for Theory, Practice, and Public Policy, 7 Psychol. SCIEnCE In The Pub. INTEREST 1, 13 (2006).

191 See Casey \& Jones, supra note 187, at 1197.

192 Ernest Hemingway reportedly said, "I drink to make other people interesting," but literary and social history does not lack for examples of similar sentiments. 
society; 193 reliance on alcohol instead of on developing social skills can impair them long into adulthood from learning how to be.

Use of such substances increase physical and social risks for the adolescent, and also can increase the risks that the adolescent poses to others. ${ }^{194}$ Adolescent drug and alcohol use risks harm to "brain functioning, cognition, and behavior." 195 Adolescents may be more vulnerable to the addictive and neurotoxic effects of alcohol.196 The developing brain may be negatively influenced by alcohol and marijuana, with "studies showing diminutions in neurocognitive functioning, especially attention, visuospatial functioning, and learning and retrieval of verbal and nonverbal information[.]"197 These functional impairments mimic the changes found in older patients with mild cognitive impairment or early stages of dementia. 198 Further, the brains of adolescents who use alcohol or marijuana heavily also show changes at more fundamental levels, including "morphological changes; anisotropic differences in white matter; and a more distributed functional network and recruitment of alternate brain regions." 199 The full meaning of some of these observations remains to be elucidated in future studies but general import of these changes is to suggest that the brain is functioning in less efficient ways.

193 See Melissa Dahl, Age 12 is Like a Second Toddlerhood, NYMaG SCIENCE OF Us (March 12, 2015), http://nymag.com/scienceofus /2015/03/age-12-is-like-a-second-toddlerhood.html.

194 See, e.g., Teens: Alcohol and Other Drugs, AMm ACAD. OF CHILD $\&$ ADOLESCENT PSYCHIATRY (July 2013), https://www.aacap.org /App_Themes/AACAP/docs/facts_for_families/03_teens_alcohol_and_oth er_drugs.pdf.

195 Bava \& Tapert, supra note 183, at 403.

196 See Casey \& Jones, supra note 187, at 1196.

197 Bava \& Tapert, supra note 183, at 403 (internal citations omitted).

198 See, e.g., Stella Karantzoulis \& James E. Galvin, Distinguishing Alzheimer's Disease From Other Major Forms of Dementia, 11 ExPERT REV. NEUROTHERAPEUTICS 1579 (2011) (describing visuospatial deficits in early dementia and Alzheimer's Disease).

199 Bava \& Tapert, supra note 183, at 403 (internal citations omitted). 
Adolescent substance use likely implicates neurological proclivity for risky behavior, poor risk/reward evaluation, and an overvaluation of affective information. ${ }^{200}$ Studies of adolescent binge drinkers showed that subjects performed worse on a common negative learning paradigm, known as the Iowa Gambling Task (IGT), than non-drinkers. ${ }^{201}$ The IGT measures how effectively a person can learn from a negative experience and modify his or her subsequent behavior. ${ }^{202}$ fMRI data revealed heightened activity in the drinkers' left amygdala, suggesting increased sensitivity to affective information, and heightened activity in the insula, correlating with impulsivity and risky decision-making. ${ }^{203}$ No difference in cognitive control areas ${ }^{204}$ was observed, but the scientists hypothesized that this could result from a lack of study power or the limited research subject sample. ${ }^{205}$ Overall, this study suggested that many of the primary decision-making difficulties faced by adolescents correlate with binge drinking.

The results studies suggest that the relationship between comparatively poor decision-making and alcohol consumption run in both directions: Adolescents who initially scored lower than their peers on several dimensions of emotional control, but who were not yet binge drinkers, were more likely to report subsequent binge drinking. ${ }^{206}$

200 See id. at 406.

201 See Lin Xiao et al., Abnormal Affective Decision Making Revealed in Adolescent Binge Drinkers Using a Functional Magnetic Resonance Imaging Study, Psychology of AdDictive BehaVIors 1, 7 (2012).

202 The IGT is used to assess deficits in a variety of clinical populations, ranging from subjects that are addicted to those suffering from lesion injuries, traumatic brain injuries, and mental illnesses. Julie A. Suhr \& Melissa T. Buelow, Construct Validity of the Iowa Gambling Task, 19 Neuropsychol. REV. 102, 102 (2009).

203 Xiao et al., supra note 201, at 8.

204 Including the orbitofrontal cortex (OFC) and ventromedial prefrontal cortex (VMPC).

205 See Xiao et al., supra note 201, at 9.

206 C. Anderson Johnson et al., Affective Decision-Making Deficits, Linked to a Dysfunctional Ventromedial Prefrontal Cortex, Revealed in 10th Grade Chinese Adolescent Binge Drinkers, 46 Neuropsychol. 714, 721-22 (2008). 
Conversely, adolescents who engaged in binge drinking performed more poorly on tests of emotional regulation. ${ }^{207}$ This suggests that the relationship between adolescence and binge drinking is not entirely age-dependent. Some adolescents have relatively greater or lesser emotional selfregulation, and relatively greater or lesser susceptibility to temporal discounting and sensation-seeking. In other words, adolescents are individuals, too; it is not the case that all adolescents are equally at risk. ${ }^{208}$ However, since these vulnerabilities are more common in adolescents, and since the maturation process typically resolves these vulnerabilities in most normal individuals, a blanket prohibition on activities that key into and exacerbate them would appear to be indicated.

Is this an instance where we can move from a factual "is" to a policy "ought"? That is, do the set of biological and social facts about juvenile developmental vulnerabilities in relation to substance misuse tell us that we ought not to have a rehabilitation-focused regime rather than a deterrence-focused criminal regime?

The relationship between adolescent vulnerabilities to substance misuse, and the significant internal and external harms of substance misuse, raises more provocative questions for law than does the case of tattooing. It is still the case that no one role for law is dictated by the biological findings and social facts of adolescent substance misuse; yet, the biological and social facts suggest that certain legal regimes would be more prudent and more efficient than others in achieving the normative goals of harm reduction. There may be a dual role for law: Strong regimes of prohibition on the front end, followed by-perhaps counterintuitively-lenient or rehabilitation-focused regimes on the back-end. As teens are particularly susceptible to the negative effects of alcohol and drugs of abuse, they similarly have less control over whether they become addicted to these substances and over the ways in

207 See id. at 722-23.

208 Casey \& Jones, supra note 187, at 1197 (discussing how variable factors like alcohol dependence in the family can affect an individual adolescent's risk profile). 
which these substances affect their behavior. This suggests that strongly punitive regimes aimed at deterrence will be costly for the state, yet achieve little; teens are less likely to weigh the prospect of future punishment relative to immediate reward. ${ }^{209}$

The vulnerabilities of impulsivity and temporal discounting that make them more likely to make bad initial choices around alcohol and drugs, and to become addicted to alcohol or drugs, are the same vulnerabilities that make them relatively punishment-insensitive. The typical teen is even less likely than the typical adult to weigh the prospect of future punishment against immediate reward and be deterred by it. ${ }^{210}$ We similarly might expect even poorer judgment and self-control from an addicted teen than from an addicted adult, irrespective of punishment regimes. ${ }^{211}$ Thus, punitive deterrence regimes aimed at teens in this arena are likely to result in high spending by the state for little impact, while producing significantly negative secondary effects as teens are processed through the criminal justice system. ${ }^{212}$ And, although they are more vulnerable to the negative effects of these substances, they are more susceptible to rehabilitation. ${ }^{213}$ In considering whether juveniles should be dealt with via criminal justice system or via diversionary and treatment programs, there is a strong case that addicted juveniles need diversionary interventions to protect their developing brains from the further effects of alcohol and drugs of abuse. ${ }^{214}$

209 See supra Part II.D.

210 See Reyna \& Farley, supra note 190.

211 See Bava \& Tapert, supra note 183, at 405-06 (explaining that drug and alcohol abuse damages cognitive capacities integral to decision making above and beyond the neurological challenges adolescents already face).

212 See, e.g., Jasmine L. Tyler et al., Cost Effective Corrections: The Fiscal Architecture of Rational Juvenile Justice Systems, THE Justice POL'Y INST. (2006), available at http://www.justicepolicy.org/uploads /justicepolicy/documents/06-03_rep_costeffective_jj.pdf.

213 See 560 U.S. 48, 74 (2010) (describing adolescent offenders as "most in need of and receptive to rehabilitation.").

214 See David Gottesman \& Susan Wile Schwarz, Juvenile Justice in the U.S.: Facts for Policymakers, NAT'L CTR. FOR CHILDREN IN POVERTY 4 (2011), available at http://www.nccp.org/publications 
Drinking and drug use hit many of the same vulnerabilities as tattooing. Among them are sensation seeking, impulsivity, temporal discounting, peer influence, and the ability both to fit in and rebel. ${ }^{215}$ But the differences with drinking and drug use are that they can alter the structure and function of the developing brain, can make a person more prone to substance misuse disorders in adulthood, and can exacerbate the mood swings and depression to which teens already are prone. ${ }^{216}$ Do these factors in themselves argue for legal intervention and prohibition? Not necessarily. One could take the libertarian position (presented above, with tattooing) that these problems are the concern of the individual affected but are not properly the concern of the state. ${ }^{217}$ The key difference, however, between the case of tattooing and the case of addictive substances is that the case for legal prohibition need not rest on aesthetic paternalism alone. Rather, unlike tattooing, substance misuse and abuse by adolescents can create significant, harmful externalities, ${ }^{218}$ and provide a clear role for law in protecting adolescents and other social stakeholders.

Thus, here, neurodevelopmental information provides more guidance to the law than it does in the case of tattooing: Prohibiting tattooing is a paternalistic and aesthetic choice on the part of the law. We understand that teens are more vulnerable to making bad decisions about tattooing, but they may be at risk of making bad decisions in many areas; whether to regulate any one versus any other stems in part from the permanence of tattoos but largely from the residual social stigma that hangs over them. With addictive substances, the forms of harm present a stronger case for regulation under most dominant views of what the law is intended to accomplish: Drug abuse can

/pdf/text_1038.pdf (explaining that community-based services, such as rehabilitation, better serve the needs of adolescents and society than other forms of juvenile incarceration).

215 See supra Part II.

216 See Bava \& Tapert, supra note 183, at 403, 405-06.

217 See supra note 175.

218 See supra note 184. 
lead to long-term developmental harm for the youth, there is little or no socially positive or expressive value to the activity (unlike tattooing, which can be a form of artistic self-expression, protected by the First Amendment), it creates externalities relating to the harms that the adolescent or future adult addicts can cause, and it can create long term costs to the state, including healthcare cases and heightened risks of future incarceration.

\section{Intentional Violence}

The case of intentional violence by adolescents presents different challenges for the law than the cases of tattooing and of addictive substances like tobacco and alcohol. Although tattooing and the use of addictive substances can present risks to the individual and create negative externalities, they are not all necessarily negative in themselves: alcohol ${ }^{219}$ or marijuana ${ }^{220}$ can be used moderately for pleasure and recreation; tattoos can have self-expressive meaning. ${ }^{221}$ Intentional violence, however, is a core form of criminal behavior that necessarily inflicts harms on others. Also, unlike experimentation with alcohol or other moderately risky behaviors, engaging in intentional violence-particularly serious intentional violence-is not a typical developmental experience for adolescents. ${ }^{222}$ This short section considers what, if anything, developmental

219 See Alcohol Use: If You Drink, Keep it Moderate, MaYo ClinIC (Feb. 11, 2014), http://www.mayoclinic.org/healthy-lifestyle/nutritionand-healthy-eating/in-depth/alcohol/art-20044551.

220 See Dirk W. Lachenmeier \& Jurgen Rehm, Comparative Risk Assessment of Alcohol, Tobacco, Cannabis, and other Illicit Drugs Using the Margin of Exposure Approach, 5 SCIENTIFIC REPORTS 1 (2015) (showing that cannabis poses a low risk of toxicity when comparing typical human dosages with dosages shown to be fatal in animal studies).

221 See Mark B. Stephens, Behavioral Risks Associated with Tattooing, 35 FAM. MEDICINE 52, 52 (2003).

222 See Adolescence, Brain Development and Legal Culpability, ABA Juvenile Justice CTR. 3 (2004) (explaining that childhood exposure to trauma is predictive of violence in adolescence. This suggests that adolescent violence arises in the wake of external, environmental factors, not as a natural part of brain development.). 
neurobiology can tell us relative to adolescents' commission of intentional violence. We do not attempt to treat this important subject thoroughly here; instead, we are using the case of intentional violence to consider the relationship between developmental neurobiology and various contexts in which intentional violence could occur, for the purpose of showing how the conduct that may appear superficially the same can have very different implications relative to developmental maturity and the ability to engage in empathy, judgment, and self-control.

In this section, we contrast two cases of intentional violence to demonstrate the ways in which an approach informed by developmental neurobiology would differ from current criminal law. Both cases present scenarios of a fifteen-year-old boy committing a battery that results in serious bodily harm. Under existing criminal law, the perpetrators in both cases likely would be waived into the adult system and tried as adults based on the nature of the crime and the level of harm that they caused. However, in the first case, the adolescent is in a context that implicates many adolescent vulnerabilities, while in the second, the adolescent has the opportunity to exercise more considered and adult-like judgment. If law aims or intends to discriminate between juvenile and adult conduct, and to provide some mitigation for adolescents based on their vulnerabilities, then the law ought to treat the perpetrators in these two scenarios differently.

We conclude that the law currently overvalues the nature of act itself and the harm caused by the act when weighing the criminal consequences that a juvenile should face. It is in the criminal area that the law most crudely and inappropriately divides juvenile from adult responsibility, by imposing adult liability on adolescents based on whether their actions caused great harm rather than by evaluating whether the actions were the product of mental processes that could be called "responsible" by an adult standard.223 Indeed, the ways in which the law draws the responsibility line between juveniles and adults is

223 See Hudson, supra note 17. 
frequently by reference to inappropriate or even irrelevant criteria. Instead, we argue that the law ought to consider the nature of the act relative whether the context in which it occurred triggered or implicated adolescent vulnerabilities. A juvenile is neither necessarily responsible nor necessarily nonresponsible for an act of violence; the real question, we suggest is: "Could we expect the typical adolescent to act with sufficient maturity and judgment in the context in which the act occurred such that he or she could be considered the equivalent of an adult under the circumstances?"

\section{Scenario A: Vulnerable to Violence}

Consider a fifteen-year-old teenager who lives in a gangridden neighborhood and is pressured to join a gang. Joining the gang presents some dangers-but so does refusing to join. Initiation requires "shanking"-or stabbing-a member of a rival gang. Egged on by friends and senior gang members, he stabs another boy in the leg. The blade hits the femoral artery and the victim nearly dies, but is saved by timely medical assistance.

In most jurisdictions, this adolescent would be waived into the adult system and tried as an adult-possibly for attempted murder but at least for aggravated battery. ${ }^{224}$ His gang membership may even be an aggravating factor in his charging and sentencing. But should that be the case?

Youth participation in gang activity has increased dramatically in the United States over the last twenty-five

224 Issue Brief 3: Less Guilty by Reason of Adolescence, MACARTHUR Found. RESEARCH NETWORK ON ADOLESCENT DEVELOPMENT AND JUVENILE JUSTICE, http://www.adjj.org/downloads/6093issue_brief_3.pdf (last visited May 17, 2015); Issue Brief 5: The Changing Borders of Juvenile Justice: Transfer of Adolescents to the Adult Criminal Court, MACARTHUR Found. RESEARCH NETWORK ON AdOlEscent DEVElopment AND JUVENILE JUSTICE, http://www.adjj.org/downloads/3582issue_brief_5.pdf (last visited Aug. $12,2015)$. 
years. $^{225}$ Youth gangs comprise loosely connected social networks and have a high turnover; 226 most teens remain in a gang for only a year or two. ${ }^{227}$ Experts disagree over how to define gangs; some focus on the fundamental role of crime in group identity ${ }^{228}$ whereas others look to "shared identity, solidarity and identified territory" as defining characteristics. ${ }^{229}$ Still others rely on self-reported gang membership to determine when an association constitutes a gang. ${ }^{230}$

Youth gang membership is strongly correlated with violent, criminal activity. ${ }^{231}$ Studies show that adolescents commit substantially more violent crimes during gang membership than before and after, ${ }^{232}$ supporting the "facilitation" model of transient gang membership. ${ }^{233}$ The facilitation model holds that gangs promote criminal behavior as opposed to attracting and selecting individuals

225 Kate O'Brien, et al., Youth Gang Affiliation, Violence, and Criminal Activities: A Review of Motivational, Risk, and Protective Factors, 18 AGGREssion VIOLENT BEHAV. 417, 418 (2013).

226 Id. at 419. (explaining the contrast between reality and the stereotype of highly organized, stable gangs: "Research suggests that while this may be true for some, in most street gangs 'leadership is ephemeral, turnover is often high, and cohesiveness only moderate and many street gangs are more a loose connection of cliques or social networks than a single, coherent whole.") (citations omitted).

227 Id. ("Most youth who identify themselves as gang members report remaining in gangs for less than 4 years, with most being members for between 1 and 2 years.") (citations omitted).

228 See Malcolm W. Klein \& Cheryl L. MaXson, Street Gang PATTERNS AND POLICIES 4-10 (2006).

229 O'Brien et al., supra note 225 , at 418 . (citation omitted).

230 Id.

231 Id. (explaining that the extent to which an individual reports being associated with a gang correlates with the level of criminal activity that individual participates in. For example, self-identified current gang members participate in more crime than individuals who have friends in gangs, and individuals not associated with gangs at all participate in even less crime).

232 Terence P. Thornberry et al., The Role of Juvenile Gangs in Facilitating Delinquent Behavior, 30 J. Res. CRIME \& DeLInquency 55 (1993).

233 O'Brien, supra note 225, at 419-20. 
already prone to delinquency. ${ }^{234}$ Risk factors in numerous domains (individual, family, peer, school, and community) predict an adolescent's eventual gang membership and violent criminal activity. ${ }^{235}$ These domains overlap with the unique vulnerabilities of the developing brain, especially with respect to peer influence and identity formation. Peer groups like gangs strongly influence teenage beliefs and values through repeated exposure to the group's accepted normative structures and by reducing exposure to alternative models. ${ }^{236}$ Acceptance and approval within a group plays into teens' overvaluation of affective information, and social alienation has been found to be a risk factor for gang membership and violence.237 Thus gangs can provide a source of social status, respect, and friendship, especially for individuals in socioeconomic life situations that lack structured, pro-social group activities. ${ }^{238}$

At the individual level, gang membership and youth violence have been correlated with emotional reactivity, impulsivity, sensation-seeking, and risk taking. ${ }^{239}$ Studies show that youth tend to leave gangs as they age and

234 Marvin D. Krohn \& Terence P. Thornberry, Longitudinal Perspectives on Adolescent Street Gangs, in THE LONG VIEW OF CRIME: A SYNThesis of Longitudinal RESEARCH 128-60 (Akiva M. Liberman ed., 2008); But cf. Rachel A. Gordon et al., Antisocial Behavior and Youth Gang Membership: Selection and Socialization, 42 CRIMINOLOGY 55 (2004) (suggesting that a synthesis of facilitation and selection governs gang membership, based on data showing that prior to joining a gang, youth often already engage in criminal activity, which increased during gang membership.).

235 O'Brien, supra note 225, at 420.

236 See KLEIN \& MAXson, supra note 228, at 4; David C. Pyrooz et al., Continuity and Change in Gang Membership and Gang Embeddedness, 50 J. RES. CRIME \& DELINQUENCY 239 (2012).

237 O'Brien, supra note 225, at 421.

238 See also Emma Alleyne \& Jane L. Wood, Gang Involvement: Social and Environmental Factors, 60 CRIME \& DELINQUENCY 547 (2014); Nat'L Research Council of the Nat'L ACADS., Reforming JUVENILE JUSTICE: A DEVELOPMENTAL APPROACH 105-06 (2013).

239 See KLEIN \& MAXSON, supra note 228, at 4; O’Brien, supra note 225 , at 421 . 
mature, ${ }^{240}$ supporting the notion that the neurological vulnerabilities that dissipate as a teenager grows out of adolescence predispose youth to gang membership.

Our hypothetical teen lives in a perfect storm of neurological and socioeconomic risk factors for gang membership and associated violence. Gangs are peer pressure mechanisms. They play into all of the age-typical adolescent neurological vulnerabilities: Temporal discounting or the "short future"; impulsivity; poor risk/reward calculations that overvalue positive (even if unlikely) payoffs; discounting negative outcomes, even highly likely negative outcomes; the need for peer approval; and the use of the social group for identity formation. ${ }^{241}$ Gang membership provides companionship and status as well as exciting, if short-sighted, opportunities for gaining recognition and respect in the community. ${ }^{242}$ Adolescents who experience poor-quality or absent parental modeling, poverty, and low quality schools are especially at risk. ${ }^{243}$ They may also be violently pressured to join gangs or know that they will be the gang's victims if they are not its members. ${ }^{244}$ Under the pressure of peer influence and the lack of alternatives (or lack of ability to perceive and access alternatives), joining and participating in a gang could feel inexorable.

Nonetheless, the consequences of his initiatory act of violence are severe. The victim was seriously injured and could have died. Additionally, the teen now faces severe legal penalties that may change the course of his life. Under the principle of "adult crime, adult time," a juvenile can be waived into the adult criminal justice system when he causes a certain level of harm. ${ }^{245}$ Accordingly, penalties

240 Ross Hastings et AL., Leaving CRIminal Youth Gangs: Exit StRATEgIES AND PROGRAMs (2011).

241 See supra Part II.

242 See O'Brien, supra note 225, at 422.

243 See id. at 421.

244 See Straight Talk About Youth Gangs: Facts for Educators, Nat'L Crime Prevention Council 1, http://www.ncpc.org /programs/teens-crime-and-the-community/publications-1/adult2-pdf (last visited Aug. 12, 2015).

245 See Hudson, supra note 17. 
can include life without parole and, until the 2011 Roper decision, even the death penalty. ${ }^{246}$

Should these policies take into consideration the unique neurological deficiencies of adolescents? In Graham, the Supreme Court found that for non-homicide crimes, the purposes of punishment do not apply as strongly to juveniles: impulsivity and poor risk-reward calculations make deterrence likely to fail; that since juveniles are still developing, rehabilitation is a real possibility and they need not be incapacitated for life; and that retribution simply does not support life without parole for juveniles. ${ }^{247}$

\section{Scenario B: Deliberate Violence}

Now consider a same-age adolescent who lives in an affluent suburb and goes to a prosperous public high school. He begins dealing marijuana and prescription drugs at his school, making thousands of dollars a month. He learns that another boy in his class plans to turn him into the school principal. To prevent the other boy from turning him in, and to make a statement to any other students who might do the same, he stabs this boy in the leg - hitting the femoral artery and nearly killing him, but for timely medical intervention.

This situation involves a serious, violent homicide crime, just like the first scenario. But it does not implicate the same adolescent neurological vulnerabilities. Unlike the peer pressure involved in joining and participating in a gang, this adolescent acted independently. He neither had peers directly pressuring him to engage in violence nor would his identity in his community be placed at risk if he failed to commit a violent act, particularly since he lives in a community that does not valorize (or require) violence. His act was not impulsive: He deliberately planned the attack for the rational purpose of preserving his business. Moreover, the act is not one that is rewarding in itself (for typical individuals), so the typical teen overvaluation of positive reward also is not operative here. Some typical

246 See supra Part I.A.

247 See 560 U.S. 48 (2010); see supra Part I.A. 
adolescent vulnerabilities may have contributed to his decision; temporal discounting may be at work, as he may not appreciate the impact his act could have on his ownand his victim's-future. He also has a teen's typical psychosocial and experiential limitations, and a teen's (average) greater ability to be rehabilitated. Nevertheless, his decision and action did not arise in a context that causes the typical adolescent to make poor decisions. Plausible arguments for mitigation based on his age could be made, but here the weight of neurobiological factors would suggest that, in this context and on these facts, the adolescent is not significantly different from the adult.

\section{RECOMMENDATIONS \& CONCLUSION}

What we see in the various regimes governing adolescent conduct are a set of approaches to balancing stakeholder interests but that share a feature in common: the notion that adolescents lack judgment generally. ${ }^{248}$ In some areas, adolescents are allowed to exercise limited or conditional autonomy, but often less because the law deems them to be responsible decision-makers than for reasons of social expedience: Allowing adolescents to work, for example, is historically rooted in traditional agrarian practices and remains important to the economic wellbeing of many families today. ${ }^{249}$ Where adolescents are endowed by law with adult-like responsibility, the law may do so without considering the qualities of the adolescent; rather, the law considers the culture's overall normative judgment about the act. To be more clear: The criminal law imposes adult responsibility on adolescents when adolescents cause significant harm-harm that mandates, normatively, strong moral condemnation, which we conventionally express through criminal punishment. ${ }^{250}$ We engage in motivated

248 See supra Part II (describing the adolescent brain's neurological limitations on decision making).

249 See David H. Wegman et al., Protecting Youth At Work: Health, Safety, and Development of Working Children and Adolescents in the United States, NAT'L ACADEMIEs PRESS 146, 151 (1998).

250 See Hudson, supra note 17. 
reasoning about whether the juvenile was acting as a juvenile or as an adult, reasoning that supports our intuitive desire to allow or to punish particular activities, not our rational assessment of the degree of the juvenile's ability to engage in mature reasoning and conduct relative to the particular domain under consideration.

But adolescents are not uniformly lacking judgment across the board. Nor are they more responsible and mature in the areas in which the law imposes adult-like responsibility or culpability upon them. Instead, juveniles mature in uneven ways. ${ }^{251}$ They have particular strengths and particular disabilities. These strengths and disabilities may be entirely independent of whether the adolescents cause harm to themselves or others. Indeed, juveniles may be particularly nonresponsible - in a developmental senserelative to the actions that have the capacity to cause the greatest harm. Teens are, by virtue of age and immaturity, most likely to engage in reckless driving, reckless drinking, reckless sex, and reckless use of violence. These are all areas in which adult like responsibility may be imposed on them-from freedom to marry, to freedom to drive, to full adult criminal responsibility for causing serious bodily harm or death.

In tandem with the findings of juvenile developmental neurobiology, legal regimes should balance the interests of other stakeholders and the capacities of the various institutions that are implicated in particular legal regimes. We suggest that lawmakers can impose some discipline on the process of making laws for juveniles and balancing the interests of stakeholders and the capacities of institutions by adopting an explicit use of a matrix. We suggest that lawmakers think of the relationship between juvenile neurodevelopmental factors, legal and social norms, stakeholder interests, and institutional considerations, as relating in the following way: Imagine a set of juvenile capacities and vulnerabilities on one axis of a matrix. The other axes of the matrix consist of the interests of other stakeholders, the capacities of institutions, the presence of

251 See supra Part II (describing how the subcortical and cognitive control systems mature at different times and rates). 
important or controlling social norms, and the signaling function of the law. Like the neurodevelopmental information itself, the matrix does not determine the particular outcome. Rather, it allows for clarity about the choices and trade-offs within any particular legal regime. This moves us away from an insufficiently granular, and often unproductive, discourse about whether juveniles are, or are not, sufficiently responsible to have a particular legal form of autonomy or responsibility. Instead, there can be a multidimensional assessment of juvenile capacities in relation to the needs and rights of other stakeholders and the broader societal norms and concerns that animate the need or desire for a legal regime in the first place.

We do not purport to construct here the definitive matrix of all the legal, social, and stakeholder concerns that lawmakers or policymakers might analyze. The neurodevelopmental criteria are the clearest. These are provided by the science of juvenile brain development, and include the various juvenile vulnerabilities discussed throughout this paper. The legal and normative criteria are less definite and more contingent, but several criteria on each dimension may be relatively uncontroversial and shared across legal and social contexts. On the dimensions of stakeholder interests and institutional capacities, a decision matrix might include, e.g., whether the issue implicates a parent's right to determine the child's upbringing; whether a parent or institution could suffer civil or criminal liability for the juvenile's action; and whether an institution has an interest in controlling the behavior in question for purposes of maintaining order (as in a school setting). On the normative dimension, a decision matrix might include factors such as, e.g., whether the behavior creates significant externalities or risks to others; social or conventional moral attitudes toward the behavior; the importance of the liberty or privacy interests implicated by the activity; or any of numerous other potential normative concerns.

The strongest case for prohibitive or protective regulation would exist where the action or behavior that would be regulated by law: 
- Significantly implicates one or more typical adolescent neurodevelopmental vulnerabilities;

- Creates significant costs or risks for other stakeholders;

- Impinges on a parent's right to direct the upbringing of the child to a greater degree than it allows for the adolescent to engage in expressive autonomy or self-creation, and/or does not have significant expressive autonomy meaning for the adolescent; and

- Is normatively undesirable in itself. The weakest cases for prohibitive or protective regulation would exist where the action or behavior that could be regulated by law:

- Does not significantly implicate one or more typical adolescent neurodevelopmental vulnerabilities because, for example, it concerns an area where the teen is not subject to peer influence or where there is not positive risk-taking or positive reward that is unduly attractive;

- Has minimal impact for other stakeholders;

- Does not impinge, or only limitedly impinges, on a parent's right to direct the upbringing of the child;

- The activity or behavior may be an important component of self-development, autonomy, or identity formation; and

- Is at least normatively neutral.

Taking this idea of the matrix, we can re-evaluate the several cases discussed in the part above and ask whether the structure of the legal regimes and the related legal outcomes should be different. With each of these casesand, indeed, with any legal issue-we can ask not just "Are juveniles sufficiently responsible to engage in, or to be punished for, for X activity?" Instead, we can disaggregate what "responsibility" means and ask, "Does this activity implicate the particular vulnerabilities of juveniles, 
suggesting a role for legal limits? If so, what are the other relevant normative and institutional considerations that may shape whether the activity is regulated and the form that the regulation takes?"

After analyzing the target behavior on a matrix that allows us to cross-evaluate neurodevelopmental, legal, and normative considerations, a result might emerge that some form of legal control or regulation would be prudent. The question then remains, "What should the law do?" There are, generally, three choices: The law may prohibit, protect, or punish. The law may prohibit juveniles from smoking tobacco (and punish those who sell it to juveniles, not punish juveniles themselves for smoking). The law may protect juveniles from working more than a certain number of hours, or may protect them from the sexual advances of adults. And the law may punish juveniles for breaking criminal laws and causing harm to others, either less than or the same as it punishes adults. Our proposed matrix (we suggest) indicates where legal regulation may be called-for.

Normative criteria, not neurodevelopmental ones, set the agenda for whether the law will protect, prohibit, or punish. Considering neurodevelopmental factors in tandem with the law's normative purposes, though, can nevertheless help determine whether a particular legal regime is consonant with its stated purposes or whether it inadvertently works at cross-purposes with its own aims. Juveniles' capacities, their strengths and weaknesses, can inform the law to create regimes that are tailored to better effectuating the law's purposes. Developmental neurobiology is one, and only one, aspect of creating legal regimes that are appropriate to how adolescents really are-how they are in their bodies and brains and social experience. All areas in which some aspect of the law rests upon assumptions about what humans are like-how mature we are, how responsible we are, what kinds of decision-makers we are, what capacities we have-can be informed, although not determined, by neuroscientific information. Using neurodevelopmental information to help craft legal regimes for adolescents is a model or microcosm for how more generally to craft regimes that integrate 
neurodevelopmental and neuroscientific information. Neither juveniles, nor any other subject of the law, exist in isolation; all are components of webs of relationships and of sets of stakeholder and institutional interests, each of which should be understood with clarity so that the law as it exists is aligned with its purposes. 